\title{
əIntercomparison of MJO Column Moist Static Energy and Water Vapor Budget among Six Modern Reanalysis Products
}

\author{
Pengfei Ren,,${ }^{\mathrm{a}, \mathrm{b}, \mathrm{c}}$ Daehyun Kim, ${ }^{\mathrm{d}}$ Min-Seop Ahn, ${ }^{\mathrm{e}}$ Daehyun Kang, ${ }^{\mathrm{d}}$ And Hong-Li Ren ${ }^{\mathrm{a}, \mathrm{c}, \mathrm{f}}$ \\ ${ }^{a}$ State Key Laboratory of Severe Weather, Chinese Academy of Meteorological Sciences, Beijing, China \\ ${ }^{\mathrm{b}}$ University of Chinese Academy of Sciences, Beijing, China \\ ${ }^{\mathrm{c}}$ Laboratory for Climate Studies, China Meteorological Administration, Beijing, China \\ ${ }^{\mathrm{d}}$ Department of Atmospheric Sciences, University of Washington, Seattle, Washington \\ ${ }^{\mathrm{e}}$ Lawrence Livermore National Laboratory, Livermore, California \\ ${ }^{\mathrm{f}}$ CMA-NJU Joint Laboratory for Climate Prediction Studies, China Meteorological Administration, Beijing, China
}

(Manuscript received 19 August 2020, in final form 28 December 2020)

\begin{abstract}
This study conducts an intercomparison of the column-integrated moist static energy (MSE) and water vapor budget of the Madden-Julian oscillation (MJO) among six modern global reanalysis products (RAs). Inter-RA differences in the mean MSE, MJO MSE anomalies, individual MSE budget terms, and their relative contributions to the propagation and maintenance of MJO MSE anomalies are examined. Also investigated is the relationship between the MJO column water vapor (CWV) budget residuals with the other CWV budget terms as well as with the two parameters that characterize cloud-radiation feedback and moisture-convection coupling. Results show a noticeable inter-RA spread in the mean-state MSE, especially its vertical structure. In all RAs, horizontal MSE advection dominates the propagation of the MJO MSE while column-integrated longwave radiative heating and vertical MSE advection are found to be the key processes for MJO maintenance. The MSE budget terms directly affected by the model parameterization schemes exhibit high uncertainty. The differences in anomalous vertical velocity mainly contribute to the large differences in vertical MSE advection among the RAs. The budget residuals show large inter-RA differences and have nonnegligible contributions to MJO maintenance and propagation in most RAs. RAs that underestimate (overestimate) the strength of cloud-radiation feedback and the convective moisture adjustment time scale tend to have positive (negative) MJO CWV budget residual, indicating the critical role of these processes in the maintenance of MJO CWV anomalies. Our results emphasize that a correct representation of the interactions among moisture, convection, cloud, and radiation is the key for an accurate depiction of the MJO MSE and CWV budget in RAs.
\end{abstract}

KEYWORDS: Madden-Julian oscillation; Moisture/moisture budget; Reanalysis data

\section{Introduction}

Global reanalysis products (RAs) provide the best estimates of the true state of the atmosphere and ocean and have been widely used in weather and climate research. Since the first RA that covers a multidecade period was made available by the National Centers for Environmental Prediction and the National Center for Atmospheric Research (NCEP-NCAR; Kalnay et al. 1996), several organizations around the world, including the National Aeronautics and Space Administration (NASA), the European Centre for Medium-Range Weather Forecasts (ECMWF), and the Japan Meteorological Agency (JMA), have established their respective RAs and the subsequent upgraded versions. The refinement of the model configurations, the improvement in the assimilation scheme, and the increase in the quantity and quality of assimilated observations have significantly enhanced the data quality of the latest generation of RAs (e.g., Gelaro et al. 2017; Hersbach et al. 2019).

The research of the Madden-Julian oscillation (MJO; Madden and Julian 1971, 1972) has been greatly benefitted by

\footnotetext{
¿ Denotes content that is immediately available upon publication as open access.
}

Corresponding author: Daehyun Kim, daehyun@uw.edu; Hong-Li Ren, renhl@cma.gov.cn the availability of RAs. As the dominant mode of intraseasonal variability in the tropical atmosphere, MJO exhibits salient features that distinguish it from other types of convectively coupled equatorial waves, including the zonal wavenumbers 16 , the period of 30-60 days, and the eastward propagation speed of about $5 \mathrm{~m} \mathrm{~s}^{-1}$ over the Indo-Pacific warm pool (e.g., Zhang 2005). The MJO-associated convection and circulation anomalies affect global weather and climate (Zhang 2013), and thereby MJO provides a source of predictability on the subseasonal time scale (Lau and Waliser 2012) to many phenomena, including regional extreme weather events (e.g., Ren and Ren 2017; Ren et al. 2018).

Since the discovery of the MJO, various theories have been proposed to explain the salient features of MJO (e.g., Zhang 2005; Wang 2012; Zhang et al. 2020; Jiang et al. 2020). Recently, a view that considers the MJO as a "moisture mode" emerged (e.g., Raymond 2001; Raymond et al. 2009; Sobel and Maloney 2012, 2013; Adames and Kim 2016; Fuchs and Raymond 2017). Readers are referred to Adames et al. (2020), Zhang et al. (2020), and Jiang et al. (2020) for dedicated reviews of the recent developments of this particular theoretical framework. In the moisture mode theory, the maintenance and propagation of MJO are explained by those of column water vapor (CWV) anomalies. Therefore, understanding processes that are key to the maintenance and propagation of MJO requires examining the evolution of CWV anomalies. 
TABLE 1. A list of published studies that examined (third column) MSE/moist entropy and (fourth column) moisture budget of the MJO. The number of studies in each year (each row) is indicated in the second column.

\begin{tabular}{|c|c|c|c|}
\hline Year & No. & MSE or moist entropy budget & Moisture budget \\
\hline 2007 & 1 & & Benedict and Randall (2007) \\
\hline 2009 & 1 & Maloney (2009) & \\
\hline 2010 & 1 & Maloney et al. (2010) & \\
\hline 2011 & 1 & Kiranmayi and Maloney (2011) & \\
\hline 2012 & 1 & Andersen and Kuang (2012) & \\
\hline 2013 & 3 & Arnold et al. (2013); Sooraj and Seo (2013); Wu and Deng (2013) & \\
\hline 2014 & 7 & $\begin{array}{l}\text { Hannah and Maloney (2014); Kim et al. (2014); Seo et al. (2014); } \\
\text { Sobel et al. (2014); Subramanian and Zhang (2014) }\end{array}$ & Chikira (2014); Hsu et al. (2014) \\
\hline 2015 & 13 & $\begin{array}{l}\text { Arnold et al. (2015); Arnold and Randall (2015); Benedict et al. } \\
\text { (2015); Hannah et al. (2015); Inoue and Back (2015); Maloney } \\
\text { and Wolding (2015); Wang et al. (2015); Wolding and Maloney } \\
\text { (2015); Yokoi and Sobel (2015) }\end{array}$ & $\begin{array}{l}\text { Adames and Wallace (2015); Feng } \\
\text { et al. (2015); Tseng et al. (2015); } \\
\text { Wolding and Maloney (2015); } \\
\text { Yokoi (2015) }\end{array}$ \\
\hline 2016 & 7 & $\begin{array}{l}\text { Carlson and Caballero (2016); DeMott et al. (2016); Pillai and } \\
\text { Sahai (2016); Pritchard and Yang (2016); Wolding et al. (2016) }\end{array}$ & $\begin{array}{l}\text { Adames et al. (2016); Chen } \\
\text { et al. (2016) }\end{array}$ \\
\hline 2017 & 10 & $\begin{array}{l}\text { Adames et al. (2017); Gonzalez and Jiang (2017); Hanf et al. } \\
\text { (2017); Jiang (2017); Kim et al. (2017); Kim (2017); Wang et al. } \\
\text { (2017); Wolding et al. (2017) }\end{array}$ & Adames (2017); Hsu and Xiao (2017) \\
\hline 2018 & 7 & $\begin{array}{l}\text { Jiang et al. (2018); Khairoutdinov and Emanuel (2018); Shi et al. } \\
\text { (2018); Stan (2018); Takasuka et al. (2018) }\end{array}$ & $\begin{array}{l}\text { Ahmed and Schumacher (2018); Hung } \\
\text { and Sui (2018) }\end{array}$ \\
\hline 2019 & 6 & Das et al. (2019); DeMott et al. (2019); Yasunaga et al (2019). & $\begin{array}{l}\text { Huang et al. (2019); Ling et al. (2019); } \\
\text { Wei and Ren (2019) }\end{array}$ \\
\hline 2020 & 4 & Ahn et al. (2020ab); Wang and Li (2020) & Kang et al. (2020) \\
\hline
\end{tabular}

As the moisture mode theory drew attention as a plausible explanation of the MJO, analyzing the column moist static energy (MSE) or moist entropy budget of MJO, which is analogous to the CWV budget under the strict weak temperature gradient (WTG) approximation (Charney 1963; Sobel et al. 2001), has become popular in the studies of MJO in the last decade (Table 1). Note that earlier analyses of the MJO MSE budget have been performed before the moisture mode theory was fully established (e.g., Benedict and Randall 2007; Maloney 2009), and were influenced more by the rechargedischarge paradigm (Bladé and Hartmann 1993; KemballCook and Weare 2001), in which the gradual buildup of MSE anomalies in the lower troposphere before the onset of MJO convection is emphasized.

A comprehensive column MSE budget of MJO was first analyzed by Maloney (2009) using general circulation model (GCM) simulation data. Focusing on the time evolution of column MSE and its budget terms in the western Pacific (WP), he found that meridional advection dominated MSE recharging and discharging before and after the onset of MJO convection, respectively. Meridional advection was suggested to be the key propagation mechanism of the MJO in the model. He also showed that the modulation of synoptic eddy activity by the MJO-scale wind anomalies explained a large fraction of meridional advection. Surface latent heat flux anomalies were found to oppose the tendency by horizontal advection, slowing down the eastward movement of MJO MSE anomalies.

Kiranmayi and Maloney (2011) expanded the analysis performed by Maloney (2009) to the entire tropics. They used two RAs constructed by NCEP-Department of Energy (NCEPDOE; Kanamitsu et al. 2002) and ECMWF [ECMWF interim reanalysis (ERA-I); Dee et al. 2011] and the results from the two products were compared with each other and to the model results of Maloney (2009). Across the Indo-Pacific warm pool, they found that horizontal advection contributed significantly to MSE tendency. Vertical advection was found to play a bigger role in the propagation of MSE anomalies, especially over the WP, in RAs than in Maloney (2009) results. Longwave radiative heating and surface latent heat flux anomalies were found to help maintain MJO MSE anomalies.

While examining the MJO MSE budget in an aquaplanet simulation, Andersen and Kuang (2012) developed a pattern projection method with which one can quantify the relative importance of individual budget terms on MSE growth and MSE propagation (see Fig. 8 for an example). The pattern projection method was adopted by many subsequent studies (e.g., Arnold et al. 2013; Adames et al. 2017; Jiang 2017). Andersen and Kuang (2012) found that horizontal MSE advection and longwave radiative heating are the essential processes for the propagation and maintenance of MJO MSE anomalies, respectively, in support of the conclusions of Maloney (2009) and Kiranmayi and Maloney (2011).

The diagnostics framework for the MJO MSE budget analysis developed by the abovementioned earlier studies (Maloney 2009; Kiranmayi and Maloney 2011; Andersen and Kuang 2012) has been widely used in the studies of MJO (Table 1). Examples of the studies that employed the MJO MSE or moisture budget analysis include examining the differences between MJO events that cross the Maritime Continent (MC) and those that do not ("MC barrier effect"; e.g., Kim et al. 2014a; Feng et al. 2015; DeMott et al. 2019), investigating processes responsible for the southward "detouring" of the MJO during austral summer (e.g., 
Kim et al. 2017), analyzing changes in MJO characteristics in a warmer climate (e.g., Arnold et al. 2013, 2015; Carlson and Caballero 2016; Adames et al. 2017; Wolding et al. 2017), evaluating the effect of the mean state on GCMs' ability to simulate the MJO (e.g., Jiang 2017; Kang et al. 2020). As another example, DeMott et al. (2016) performed a thorough examination of MJO MSE budget in ERA-I with a particular focus on surface flux feedbacks to MJO.

While diagnosis of the MJO MSE budget in a model simulation can shed lights on the maintenance and propagation mechanisms of the simulated MJO, the question of whether the model simulates MJO for the right reason can be answered only by evaluating the model results against the corresponding observations. Reanalysis products have played a pivotal role as the reference dataset in this regard. Due to the necessity of the large number of atmospheric field variables as well as radiative and turbulent surface heat fluxes in an MSE budget analysis (section 2b), the MSE budgets in the observed MJOs are examined almost exclusively in the RAs (e.g., Kiranmayi and Maloney 2011; Kim et al. 2014a; Wang and Li 2020), with a few exceptions that used observations from field campaigns (Sobel et al. 2014; Yokoi and Sobel 2015; Inoue and Back 2015).

The goal of the present study is to examine the columnintegrated MSE and CWV budget of the MJO in six modern RAs. While RAs are often considered as "observations," it is well known that notable differences between RAs exist in many aspects of the weather-climate system (e.g., Kim et al. 2014b; Chen et al. 2014; Lindsay et al. 2014; Sakaeda and Roundy 2016; Gao et al. 2016, 2019). However, little attention has been paid to the question of whether and how much the MJO MSE and CWV budget is represented differently in different RAs. To our best knowledge, only Kiranmayi and Maloney (2011) and Yokoi (2015) analyzed MJO MSE or CWV budget in more than one reanalysis dataset.

Essentially, our analysis will assess the degree to which the mean state and variability of MSE and CWV are constrained in the RAs, and there are reasons to believe that there would be nonnegligible differences between RAs, especially in water vapor. Over the warm tropical oceans, where moisture variability associated with the MJO is most pronounced, water vapor in RAs is constrained mainly by satellite observations. The differences in the list of satellite datasets assimilated for constraining moisture (e.g., Table 2 in Yokoi 2015) as well as those in the data assimilation techniques can potentially lead individual RAs to have different water vapor amount at the same location and time. Moreover, there exists a large spread among satellite retrievals. As part of the Global Water and Energy Exchanges water vapor assessment project, Schröder et al. (2019) compared CWV retrievals from various instruments, including microwave and infrared sensors, ultraviolet-visiblenear-infrared imagers, and GPS radio occultation measurements. They found a notable spread $(10 \%-15 \%)$ over the tropical oceans among satellite retrievals even in the long-term mean CWV. While identifying the root cause of the inter-RA spread may be beyond the scope of our study, we aim to provide useful information to the user community by objectively quantifying the uncertainty in MSE and CWV variability associated with the MJO.
When examining inter-RA differences in the MSE budget terms, we will focus on the processes that are directly affected by model parameterization schemes. Those terms, such as vertical MSE advection, radiative fluxes, and surface turbulent fluxes, are less constrained by assimilating observations and therefore more likely to show large differences between RAs.

A special focus will also be on the budget residual. Kiranmayi and Maloney (2011) documented a large residual in the MJO MSE budget whose magnitude was comparable to that of MSE tendency in both reanalysis datasets used. Due to the existence of nonnegligible budget residual, the reanalysis-based MJO MSE budget results have been interpreted with caveats (Kiranmayi and Maloney 2011; Kim et al. 2014a). Analysis incrementcorrection of the field variables during the data assimilation procedure-is believed to take a large portion of the MSE budget residual (Yokoi 2015; Mapes and Bacmeister 2012), while truncation errors from the finite differencing method employed to estimate gradients and using pressure level interpolated output can also contribute to the budget residual (Hill et al. 2017).

Characterizing the evolution of analysis increment during the life cycle of MJO can offer insights into model biases. Mapes and Bacmeister (2012) analyzed moisture analysis increment in the context of MJO structure in Modern-Era Retrospective Analysis for Research and Applications, version 1 (MERRA-1), and found that moisture is added by data assimilation during the preonset phase of the MJO. They suggested that deep convection is triggered in the model too early and makes columns overly dry, which is compensated by the moisture increment. In an attempt to understand the difference in MJO CWV budget between three RAs, Yokoi (2015) found a negative correlation between the strength of cloud-radiation feedback [defined by Eq. (6) below] and MJO CWV analysis increment. While supporting the argument that cloud-radiation feedback is the dominant MJO maintenance mechanism, his results also demonstrated that analysis increment offers useful insights into model biases. Following Yokoi (2015), we will examine the relationship between MJO CWV budget residual and two parameters that characterize cloud-radiation feedback and moisture-convection coupling.

The present study is organized as follows. Section 2 introduces data and methods. Section 3 presents inter-RA comparisons of the mean state, MSE anomalies, and MSE budget analysis. The potential impacts of moisture-cloud-radiationconvection feedback on the residual in CWV budget are shown in section 4 . Section 5 provides the summary and conclusions.

\section{Data and methods}

\section{a. Reanalysis and observational data}

We use six modern RAs, including MERRA-1, MERRA-2 (Gelaro et al. 2017), ERA-I, the fifth major global reanalysis produced by ECMWF (ERA5; Hersbach et al. 2019), NCEP Climate Forecast System Reanalysis (CFSR, Saha et al. 2010, 2014), ${ }^{1}$ and the Japanese 55-yr Reanalysis (JRA-55; Kobayashi

\footnotetext{
${ }^{1}$ A merged dataset of CFSR (1980-2011) and CFSRv2 (201214) will be referred to as CFSR.
} 
TABLE 2. A brief description of the global reanalysis products used in this study.

\begin{tabular}{llccc}
\hline \hline \multicolumn{1}{c}{ Name (organization) } & \multicolumn{1}{c}{ Availability } & $\begin{array}{c}\text { Assimilation } \\
\text { scheme }\end{array}$ & $\begin{array}{c}\text { Horizontal } \\
\text { resolution }\left(^{\circ}\right)\end{array}$ & Reference \\
\hline MERRA-1 (NASA GMAO) & 1979-2016 & 3D-Var & $0.5 \times 0.66$ & Rienecker et al. (2011) \\
MERRA-2 (NASA GMAO) & 1980-present & 3D-Var & $0.5 \times 0.625$ & Gelaro et al. (2017) \\
ERA-I (ECMWF) & 1979-present & 4D-Var & $0.75 \times 0.75$ & Dee et al. (2011) \\
ERA5 (ECMWF) & 1979-present & 4D-Var & $0.28125 \times 0.28125$ & Hersbach et al. (2019) \\
CFSR (NCEP) & CFSR (1979-2010)/CFSR v2 & 3D-Var & $0.5 \times 0.5$ & Saha et al. (2010, 2014) \\
& $\quad(2011$-present) & 4D-Var & $1.25 \times 1.25$ & Kobayashi et al. (2015) \\
JRA-55 (JMA) & 1979-present & & & \\
\hline
\end{tabular}

et al. 2015). A brief description of the six RAs used in our study is presented in Table 2. To facilitate the comparison between RAs, we define the multireanalysis mean (MRM) - a simple average over all six RAs - for quantities whose corresponding observations are not available (e.g., MJO MSE anomalies). While RAs are compared to MRM, it should be noted MRM is not necessarily closer to the true state than any individual RAs used.

Some observations are used to evaluate the performance of the RAs, including the outgoing longwave radiation (OLR) from NOAA satellites (Liebmann and Smith 1996) and the precipitation from Tropical Rainfall Measuring Mission (TRMM; Kummerow et al. 2000).

All data were interpolated into a uniform horizontal resolution of $2.5^{\circ}$ longitude $\times 2.5^{\circ}$ latitude to facilitate comparison between RAs. Our analysis was performed over the period that is covered by all RAs (1980-2014). It is well known that the MJO exhibits notable seasonality, with the boreal winter MJO being characterized by eastward propagation, and summer MJO activities involving significant northward-propagating component in the Indian Ocean (IO) and the WP (Yasunari 1979, 1980; Murakami et al. 1984; Lau and Chan 1986). Our analysis focuses only on the boreal winter months (November to April).

\section{b. Column-integrated MSE and CWV budget of MJO}

The dry static energy (DSE) and MSE are defined as

$$
s=C_{p} T+\Phi \quad \text { and } \quad m=s+L_{v} q,
$$

where $C_{p}$ is the specific heat of air constant pressure, $T$ is air temperature, $\Phi$ is geopotential, $q$ is specific humidity, and $L_{v}$ is the latent heat of condensation; $L_{v} q$ is often referred to as latent energy (LE).

The intraseasonal, column-integrated MSE budget in the pressure coordinate takes the following form:

$$
\begin{aligned}
\left\langle\frac{\partial m}{\partial t}\right\rangle^{\prime}= & -\left\langle\mathbf{V} \cdot \nabla_{h} m\right\rangle^{\prime}-\left\langle\omega \frac{\partial m}{\partial p}\right\rangle^{\prime}+\mathrm{LH}^{\prime}+\mathrm{SH}^{\prime} \\
& +\langle\mathrm{LW}\rangle^{\prime}+\langle\mathrm{SW}\rangle^{\prime}+\operatorname{res}_{m},
\end{aligned}
$$

where angle brackets $\langle A\rangle=\int_{p_{T}}^{p_{B}} A(d p / g)$ represent a massweighted vertical integral from 1000 to $100 \mathrm{hPa}$; the prime indicates intraseasonal anomalies; $\mathbf{V}$ is the horizontal wind vector; $\omega$ is pressure velocity; $p$ is pressure; $\mathrm{LH}$ and $\mathrm{SH}$ are surface latent flux and sensible heat flux, respectively; and LW and SW represent column-integrated longwave and shortwave radiative heating rate, respectively. We use the backward and centered finite-differencing schemes for time tendency and spatial gradient calculations, respectively. The MSE budget residual ( $\mathrm{res}_{m}$ ) is obtained by subtracting all terms except for itself on the right-hand side of Eq. (2) from the directly estimated MSE tendency. Intraseasonal anomalies of each budget terms are obtained by first subtracting the daily climatological mean and seasonal cycle (first three annual harmonics) and then bandpass filtering the resulting daily anomalies using a 20-100-day Lanczos filter (Duchon 1979). Note that anomalies are defined for each RA by subtracting its own climatological seasonal cycle.

In section 4, we also calculate the CWV budget of the MJO and examine the relationship of CWV budget residual with other CWV budget terms and measures of cloud-radiation feedback and convective moisture adjustment time scale. The intraseasonal CWV budget equation is as follows:

$$
\left\langle\frac{\partial q}{\partial t}\right\rangle^{\prime}=-\left\langle\mathbf{V} \cdot \nabla_{h} q\right\rangle^{\prime}-\left\langle\omega \frac{\partial q}{\partial p}\right\rangle^{\prime}+E^{\prime}-P^{\prime}+\text { res }_{q},
$$

where $E$ is surface evaporation and $P$ is precipitation. The CWV budget residual $\left(\mathrm{res}_{q}\right)$ is obtained similarly as in the MSE budget. As mentioned above, under the strict WTG approximation (Charney 1963; Sobel et al. 2001), the tendency of column-integrated MSE is equivalent to that of the CWV tendency.

\section{c. MJO life cycle composite}

To characterize MJO activity, various field variables, including MSE budget terms, are composited for MJO phases that are defined using the OLR-based MJO index (OMI; Kiladis et al. 2014). For a given time, the OMI consists of two scalar values (OMI1 and OMI2) that can be located in a 2D phase diagram (e.g., Wheeler and Hendon 2004). Using the position vector that begins at the origin and ends at (OMI, OMI2), MJO amplitude is estimated as the length of the position vector. The phase diagram can be divided into eight equal-sized spaces by $x$ and $y$ axes and two diagonal lines that crosses the origin. Each space corresponds to a MJO "phase." The convention is that the space that is in the third quadrant and right beneath $y$ axis represents phase 1 and the numeric increases counterclockwise to end at 8 . MJO phase on a given day is determined by the space the end of the position vector belongs to. By MJO composite of a variable, we mean the average of the variable for each MJO phase over days with 
MJO amplitude greater than 1 . We note that the results are almost identical with the multivariate MJO index (Wheeler and Hendon 2004, not shown).

\section{Mean state and MJO MSE budget in RAs}

\section{a. Mean state}

We begin by analyzing the horizontal and vertical structures of the mean MSE, DSE, and LE. As mentioned in the previous section, for each RA, anomalies are defined around its own climatological seasonal cycle. Therefore, it is worthwhile to examine the mean state and its differences between RAs. The mean state affects the MSE budget terms in various ways, in particular, through the horizontal and vertical gradient of the mean MSE. It has been reported that the ability of a model to simulate MJO is closely linked to its ability to represent the climate mean state (Zhang et al. 2006; Kim et al. 2009; Gonzalez and Jiang 2017; Jiang 2017; DeMott et al. 2019; Ahn et al. 2020a). For example, models that realistically capture the horizontal gradient of seasonal mean lower-level moisture around the $\mathrm{MC}$ region tend to show a more coherent propagation of the MJO (Gonzalez and Jiang 2017; Jiang 2017; DeMott et al. 2019; Ahn et al. 2020a).

The mean zonal and meridional gradient of MSE affects the horizontal MSE advection term, which has been suggested as the dominant moisture recharging and discharging process for MJO's eastward propagation (e.g., Kim et al. 2014a) and as a damping process (e.g., Wolding et al. 2016). Figure 1 shows the horizontal distributions of the winter-mean column-integrated MSE, DSE, and LE. In Fig. 1b, the domain mean was subtracted from each variable to better compare horizontal gradient among the three variables. The horizontal gradient of the mean MSE comes mainly from that of the mean LE whereas the mean DSE is almost horizontally homogeneous. Over the Indo-Pacific warm pool, the mean MSE is relatively high in MERRA-2 and ERA-I and relatively low in JRA-55 and CFSR. As a result, the horizontal MSE gradient across the warm pool are sharper in MERRA-2 and ERA-I and smoother in JRA-55 and CFSR. MERRA-1 and ERA5 values are close to those of MRM. Figure 1 also shows that the inter-RA difference in the mean MSE originates mainly from that of LE. CFSR is an exception in this regard, in which the mean DSE is lower than the other RAs (especially in the upper and lower free troposphere, Fig. 2e).

Figure 2 shows the vertical structures of the MRM mean MSE, DSE, and LE. Overall, DSE and LE increases and decreases with height, respectively, resulting in MSE minima at around $700 \mathrm{hPa}$ across the warm pool. Again, the longitudinal variation in MSE in the mid- to low troposphere comes from that of LE, while the mean DSE is zonally homogeneous except in the boundary layer and near $200 \mathrm{hPa}$. Also shown in Fig. 2 in the center and right panels is the warm-pool-averaged MRM, the deviation from the MRM for each RA and its standard deviation. For the mean MSE, the inter-RA differences are most pronounced in two layers: one between 950 and $800 \mathrm{hPa}$ and the other between 700 and $400 \mathrm{hPa}$ (Fig. 2c). In the lower one, which covers the upper part of the planetary boundary layer (PBL) and the lower part of the free troposphere, MERRA-1 is relatively dry and cold, whereas ERA-I, ERA5, and JRA-55 are relatively wet and warm. CFSR shows a transition from the warm/moist to the cold/moist condition between 950 and $800 \mathrm{hPa}$. Presumably, the difference in the representation of the boundary layer turbulence and ventilation of heat and moisture by deep convection scheme from PBL is what causes the inter-RA spread in this layer. The $700-400 \mathrm{hPa}$ layer is relatively wet in MERRA-1 and MERRA-2 and dry in JRA-55. The difference in LE between MERRA-2 and JRA-55 at $600 \mathrm{hPa}$ is about $4 \mathrm{~kJ} \mathrm{~kg}^{-1}$, which is $40 \%$ of the MRM value. The treatment of cumulus congestus (Johnson et al. 1999) and cloud microphysics, especially the melting process (e.g., Thayer-Calder and Randall 2009), may be caused these differences between the RAs. The vertical grid spacing near the melting level can also affect the representation of cumulus congestus (Inness et al. 2001). The substantial inter-RA spread in the mean LE shown in Fig. 2 suggests that it remains challenging to constrain moisture in the tropics through data assimilation.

\section{b. MJO MSE budget}

Figure 3a shows the longitude-phase composites of the column-integrated MSE anomaly for MRM, which well captures the coherent eastward propagation of MJO. Compared to MRM, the amplitude of MSE anomalies is larger in MERRA2, especially in the IO. In contrast, the MJO MSE anomalies are relatively weak in JRA-55 over the entire warm pool region. Interestingly, MERRA-2 and JRA-55 exhibit climatologically wetter and drier conditions than the other RAs (Figs. 1 and 2). CFSR shows considerable deviations from MRM over the MC during the transition phases (i.e., when MSE anomalies change the sign). Overall, the MJO MSE anomalies in MERRA-1, ERA-I, and ERA5 are close to those in MRM. To quantify the degree of spread among the RAs, we calculated the standard deviation of the composite MSE anomalies using the six RAs (Fig. 3b). A large inter-RA spread appears in the eastern Indian Ocean (EIO) for MJO phases 2-3 and 6-7, and in the eastern MC to WP regions for MJO phases 1 and 5, where the MRM MSE anomalies are significant. The standard deviation is about $10 \%$ of the MRM values in those areas and phases, and the deviations in MERRA-2, and CFSR, and JRA-55 are mainly responsible for the spread.

To further examine the differences in MSE anomalies between RAs, Fig. 4 shows the horizontal distribution of the MJO MSE anomalies during MJO phase 3. In the EIO region, where positive MSE anomalies peak in the MRM, MERRA-2 and JRA-55 show substantial positive and negative differences from the MRM, respectively. In CFSR, negative difference prevails in the southern MC and WP regions while a weak positive difference appears in the EIO. The difference seems to be about $90^{\circ}$ out of phase with the MSE anomaly, suggesting a time lag between the MRM MJO and that in CFSR MJO.

Figure 5 further shows MSE anomalies in longitude-pressure diagrams for MJO phase 3. The MRM MSE anomalies are tilted westward with height, with shallow MSE anomalies appearing to the east of maximum MSE anomalies. In the EIO, a large interRA differences appear in the low-to-middle free troposphere 


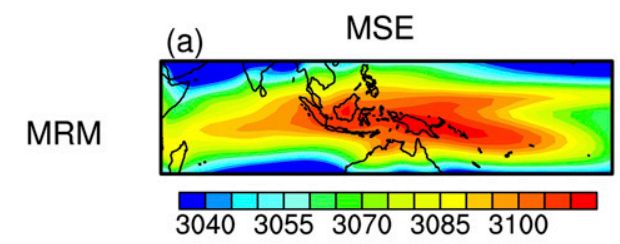

(b)

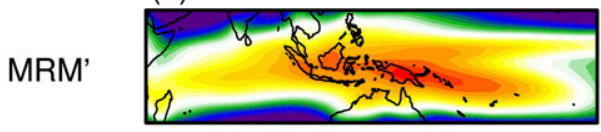

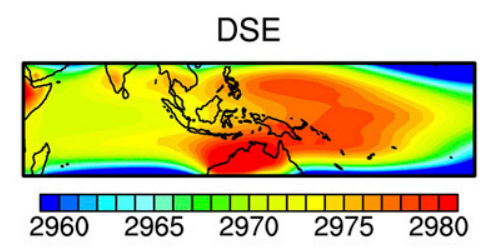

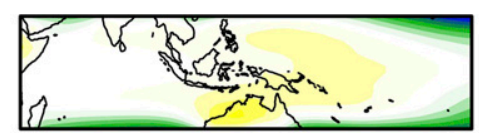

LE

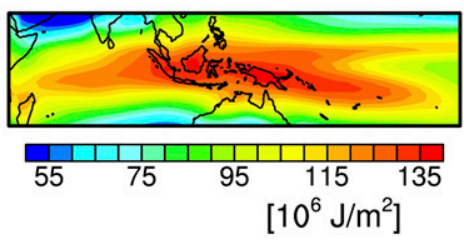

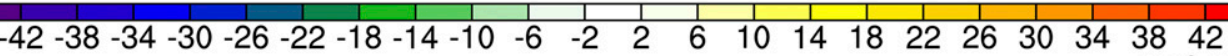 $\left[10^{6} \mathrm{~J} / \mathrm{m}^{2}\right]$}

(c)

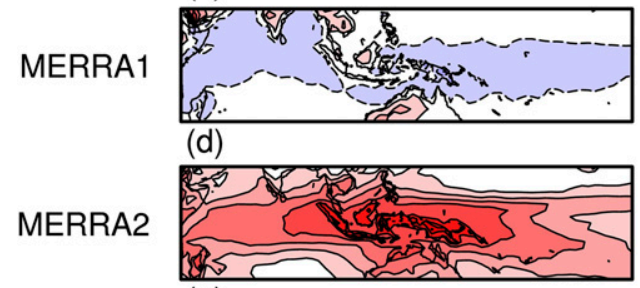

(e)

ERA-I

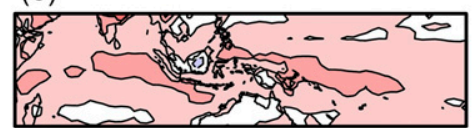

(f)

ERA5

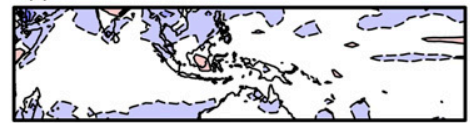

(g)

CFSR

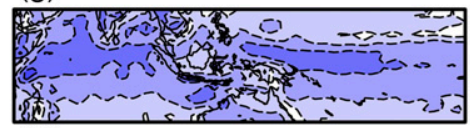

(h)

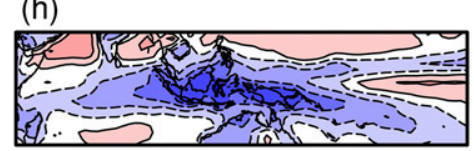

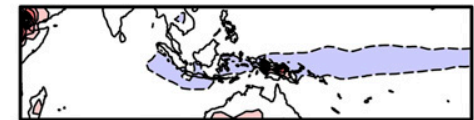
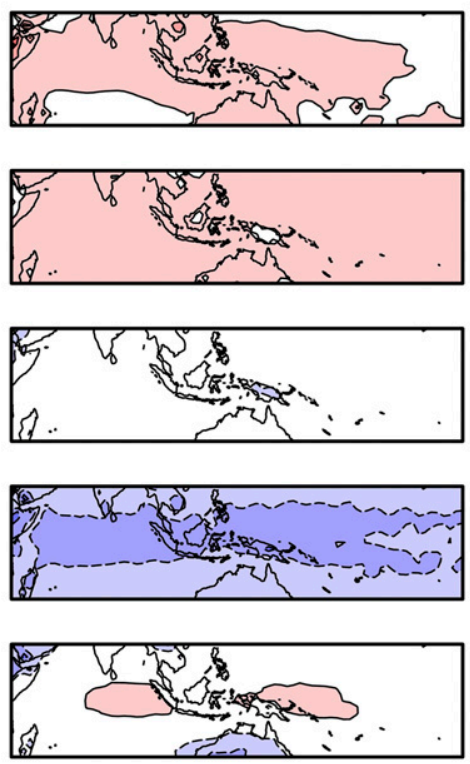
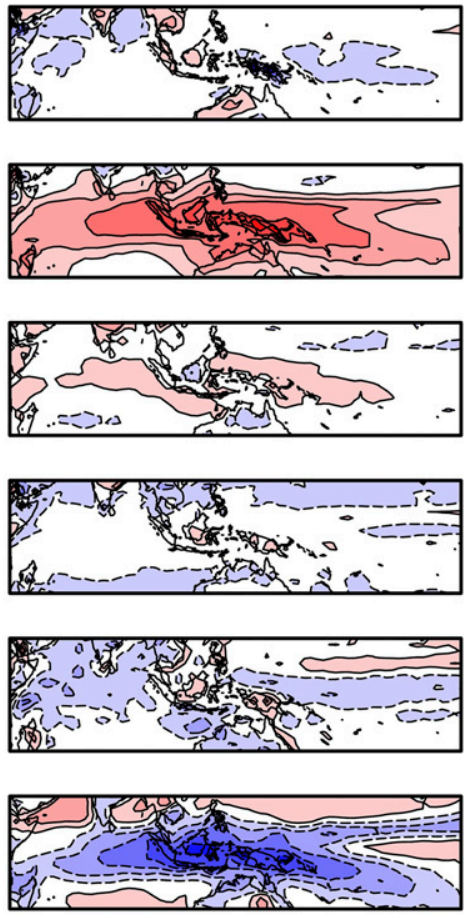

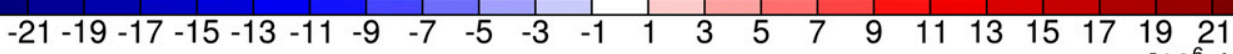

$$
\begin{aligned}
& {\left[10^{6} \mathrm{~J} / \mathrm{m}^{2}\right]}
\end{aligned}
$$

FIG. 1. (a) The MRM of (left) column-integrated MSE, (center) DSE, and (right) LE for boreal winter. (b) As in (a), except that the domain mean is removed. (c)-(h) Differences from MRM for (c) MERRA-1, (d) MERRA-2, (e) ERA-I, (f) ERA5, (g) CFSR, and (h) JRA-55. The contour interval in (c)-(h) is $2 \times 10^{6} \mathrm{~J} \mathrm{~m}^{-2}$.

(800-400 hPa), especially for MERRA-2 and JRA-55. The difference in MERRA-2 is located slightly to the west of the maximum MRM MSE and shows a westward tilted structure. The deviation in JRA-55 appears mainly where the MRM MSE anomalies peak. CFSR deviations are mainly concentrated in the lower troposphere $(1000-600 \mathrm{hPa})$ and show a dipole structure between the $\mathrm{EIO}$ and $\mathrm{MC}$ regions, which appears to be consistent with its slower MJO propagation speed. That the only coupled RA (CFSR) exhibits a lagged MJO may suggest that a low-frequency, unstable air-sea coupled mode (Wang and Xie 1998) is responsible for the MJO slow down.
In Fig. 6, the four terms that dominate the MJO MSE budget in magnitude are separately shown: horizontal advection (hAdv), vertical advection (wAdv), longwave radiative heating (LW), and surface latent heat flux (LH). In MRM, large anomalous horizontal advection of MSE appears where the MSE anomalies are changing polarity, highlighting its primary role in the propagation of the MSE anomalies. In contrast, vertical MSE advection and column longwave radiative heating show large magnitude near the positive and negative peaks of the MSE anomalies, suggesting that the two terms contribute mainly to the maintenance of the MJO MSE anomalies. The wAdv and LW terms are both directly 

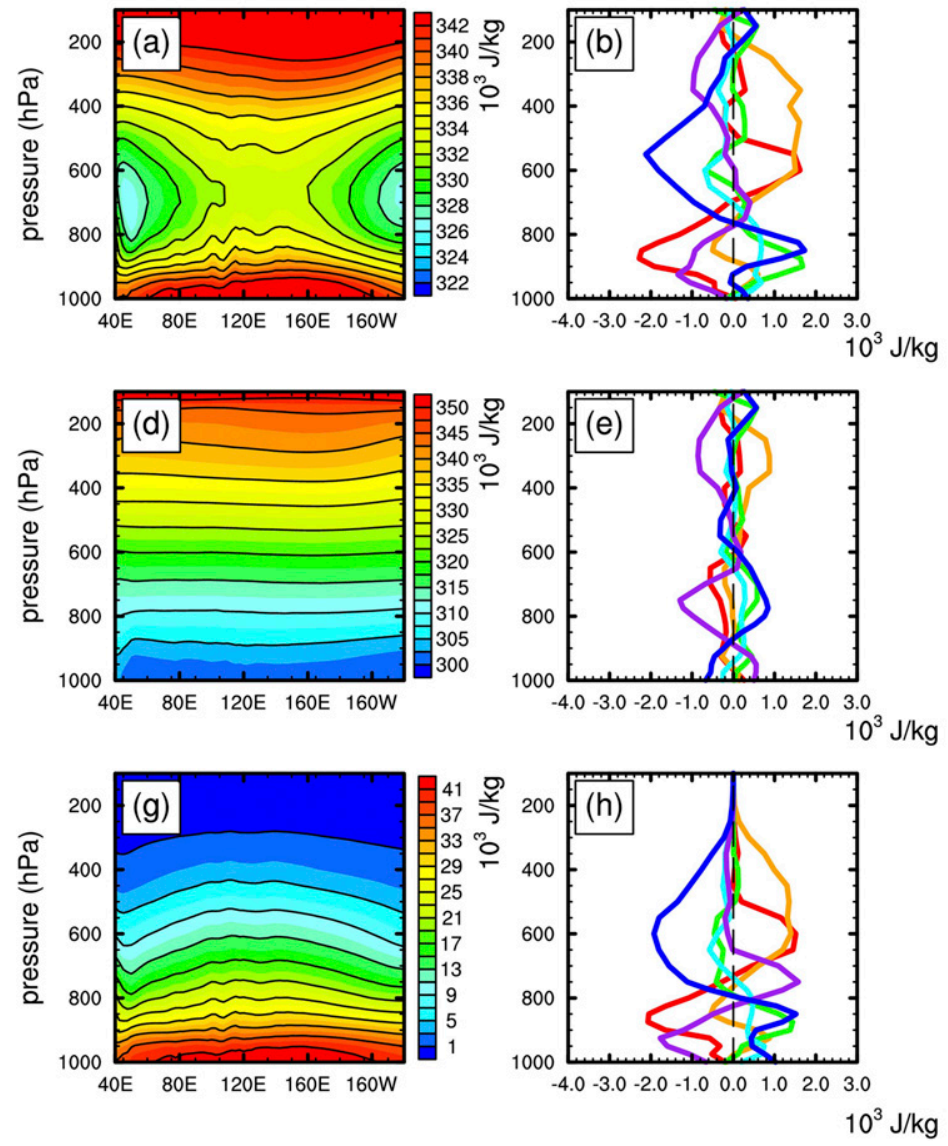
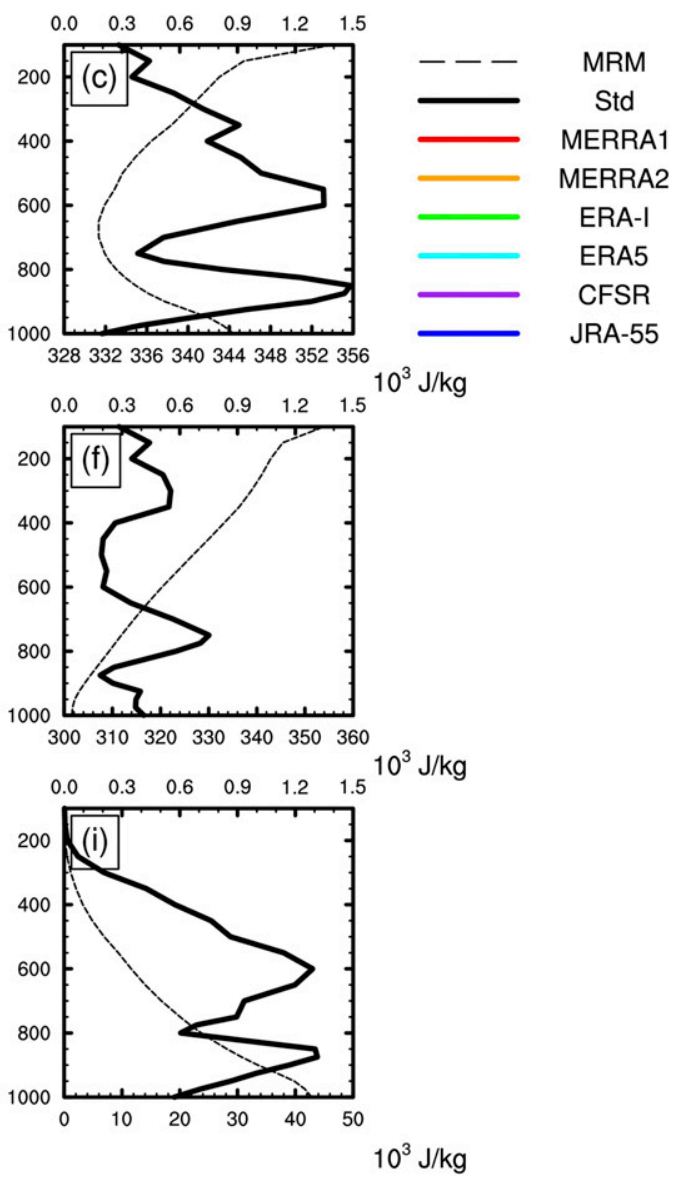

FIG. 2. (left) Longitude-pressure distribution of the boreal winter mean, equatorial $\left(10^{\circ} \mathrm{S}-10^{\circ} \mathrm{N}\right)$ (a) MSE, (d) DSE, and (g) LE in the MRM. (center) Deviation from warm-pool $\left(10^{\circ} \mathrm{S}-10^{\circ} \mathrm{N}, 60^{\circ} \mathrm{E}-180^{\circ}\right)$-averaged MRM for each RA of (b) MSE, (e) DSE, and (h) LE. (right) Warm-pool-averaged MRM and the standard deviation for each RA of (c) MSE, (f) DSE, and (i) LE. The contour intervals in (a), (d), and (g) are 2,5 , and $4 \mathrm{~kJ} \mathrm{~kg}^{-1}$, respectively.

affected by local convective activity and often tend to have the opposite signs. By slightly lagging the MSE anomalies, column LW also slows down the propagation of the MSE anomalies. Surface latent heat flux anomalies also seem to counteract the effect of horizontal MSE advection, especially over the MC.

All MSE budget terms show noticeable inter-RA spread. The difference between RAs is larger for individual budget terms than for their sum (i.e., total tendency, not shown). The role of horizontal MSE advection in moving MSE anomalies to the east seems to be stronger in ERA5 and weaker in MERRA-1. In MERRA-2 (JRA-55), horizontal MSE advection tends to dampen (amplify) MSE anomalies. Compared to MRM, the magnitude of vertical MSE advection in JRA-55 is larger, while it is smaller in CFSR. LW in the Pacific and in the Indian Ocean is relatively weak in MERRA-2 and JRA-55. LW in CFSR lags the MRM LW, exhibiting a stronger slowing effect on the MJO MSE propagation. MSE anomalies are amplified by LW more in ERA-I and ERA5 than in the other RAs. Compared to MRM, LH is represented with a much greater amplitude in CFSR. JRA-55 LH seems to damp MSE anomalies, which likely contributes to its relatively small MSE anomaly (Fig. 3).
Nonnegligible budget residual is found in all RAs (Fig. 7). In MERRA-1, MERRA-2, ERA5, and JRA-55, the budget residual tends to be in phase with the MSE anomalies, indicating that the models used to create the modern RAs need additional MSE source to maintain MJO MSE anomalies. In ERA-I and CFSR, on the other hand, budget residual appears where MSE anomalies are small, suggesting that the processes that are associated with MSE tendency are not adequately represented. Our results for ERA-I are similar to that of Wolding and Maloney (2015), who found that MSE budget residual tends to appear in the transitional phase of OLR anomalies in ERA-I.

The relative contribution of the individual MSE budget terms to the maintenance and propagation of MSE anomalies can be estimated by projecting them upon MSE anomalies and their tendencies (e.g., Andersen and Kuang 2012):

$$
\begin{aligned}
& S_{m}(F)=\frac{\left\|F^{\prime} M^{\prime}\right\|}{\left\|M^{\prime} M^{\prime}\right\|} \text { and } \\
& S_{p}(F)=\frac{\left\|F^{\prime} \partial M^{\prime} / \partial t\right\|}{\left\|\left(\partial M^{\prime} / \partial t\right)\left(\partial M^{\prime} / \partial t\right)\right\|},
\end{aligned}
$$



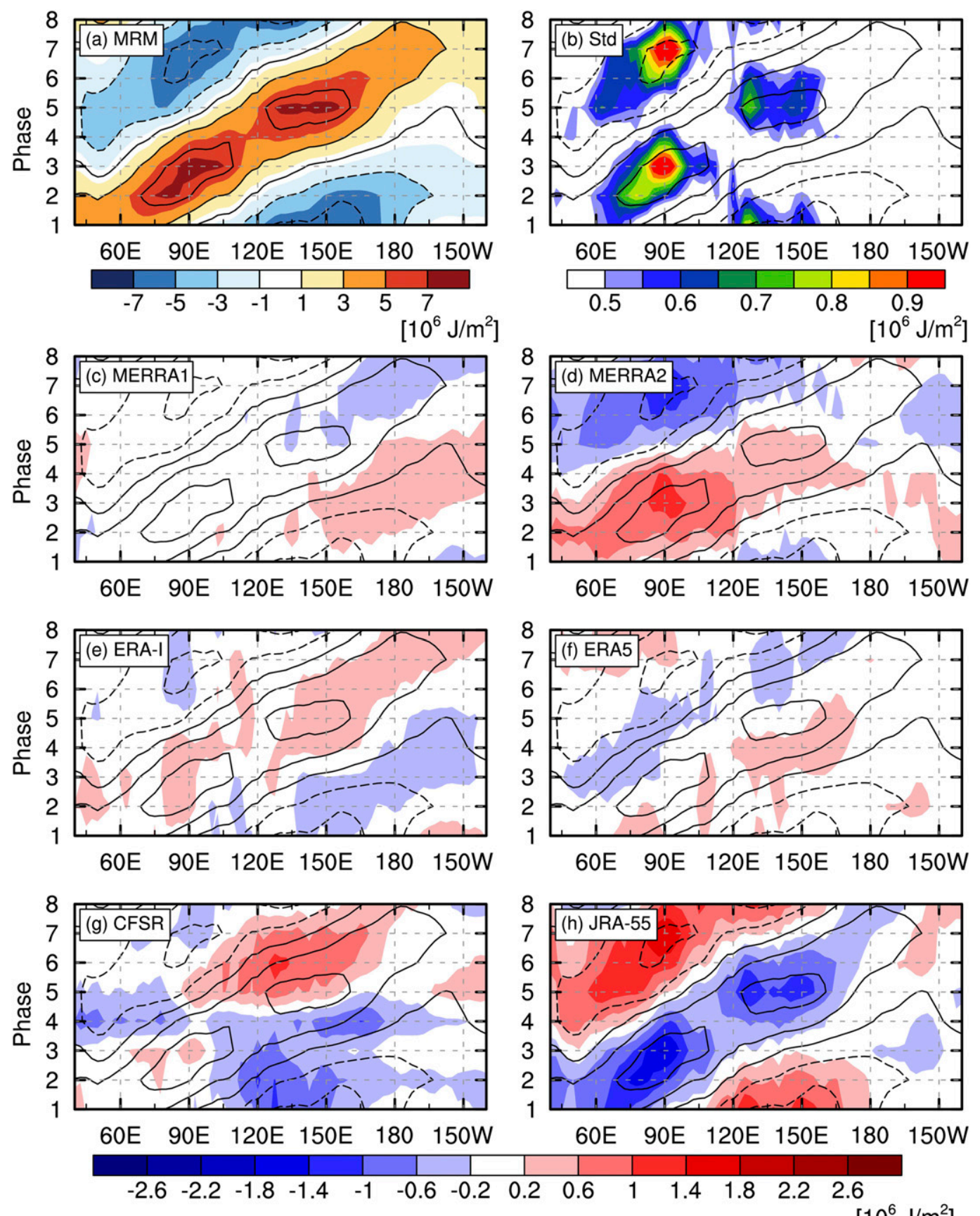

FIG. 3. (a) Longitude-phase composite of the MRM column-integrated MSE anomaly and (b) its standard deviation among six RAs in the equatorial region $\left(15^{\circ} \mathrm{S}-15^{\circ} \mathrm{N}\right)$. (c)-(h) Differences (shaded, units: $10^{6} \mathrm{~J} \mathrm{~m}^{-2}$ ) from MRM for (c) MERRA-1, (d) MERRA-2, (e) ERA-I, (f) ERA5, (g) CFSR, and (h) JRA-55. The contours represent MRM MSE anomaly (contour interval: $3 \times 10^{6} \mathrm{~J} \mathrm{~m}^{-2}$ ).

where $F^{\prime}$ and $M^{\prime}$ are MSE budget terms and MSE anomaly, respectively, and $\|A\|$ is the integral of $A$ over the domain $15^{\circ} \mathrm{S}-15^{\circ} \mathrm{N}, 60^{\circ}-180^{\circ} \mathrm{E}$, and $\mathrm{MJO}$ phases $1-8$ in the MJO phase composite diagram.

Figure 8 shows $S_{p}$ (top) and $S_{m}$ (bottom) for each term in Eq. (2) and for two derived terms: the sum of zonal and meridional advection (hAdv) and the sum of vertical advection and radiative heating (CONV). The latter derived term represents the combined effect of MSE import/export by vertical advection and the net MSE flux into the column via longwave radiative fluxes. The numbers within parentheses indicate a measure of the inter-RA spread, which is obtained for each budget term by dividing the 


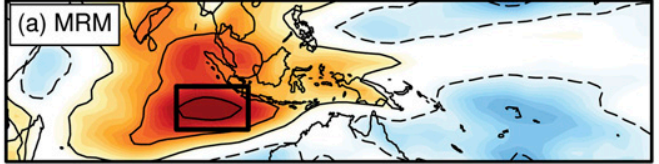

$-9-7.5-6-4.5-3-1.501 .534 .567 .59$ $\left[10^{6} \mathrm{~J} / \mathrm{m}^{2}\right]$
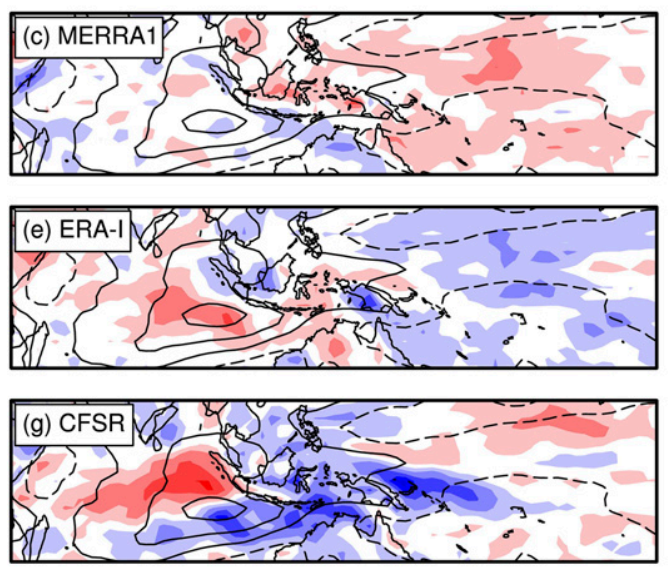
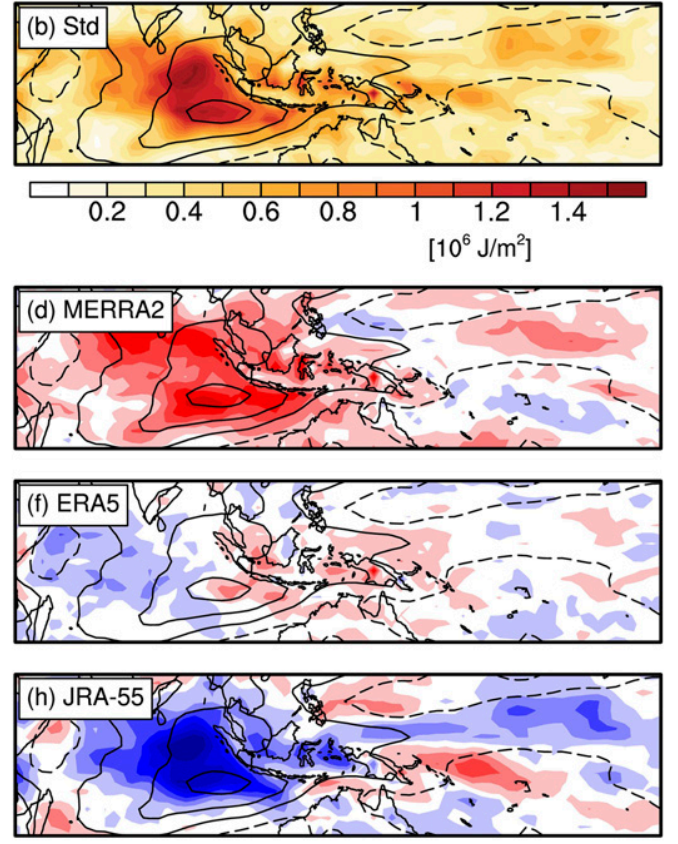
$\left[10^{6} \mathrm{~J} / \mathrm{m}^{2}\right]$

FIG. 4. (a) MJO phase 3 composite of the MRM column-integrated MSE anomaly and (b) six-RAs' standard deviation. (c)-(h) Differences from MRM for (c) MERRA-1, (d) MERRA-2, (e) ERA-I, (f) ERA5, (g) CFSR, and (h) JRA-55. The contours represent MRM MSE anomaly (contour interval: $4 \times 10^{6} \mathrm{~J} \mathrm{~m}^{-2}$ ). Note that the box in (a) covers the area of $16^{\circ}-4^{\circ} \mathrm{S}, 87.5^{\circ}-107.5^{\circ} \mathrm{E}$.

standard deviation of values from six RAs by the absolute value of its corresponding MRM value. The resulting number is shown in percentage.

Figure $8 \mathrm{a}$ indicates that, to first order, MJO MSE anomalies are moved to the east by advection processes, while surface latent heat flux and longwave radiative heating oppose the eastward propagation. Among the three advection terms, meridional advection plays a dominant role in the propagation of the MSE anomalies. Many previous studies drew similar conclusions (e.g., Kim et al. 2014a; Jiang 2017). Meridional advection is also the least uncertain process. Its inter-RA spread measured by the standard deviation is only about $4 \%$ of the MRM value. When combined with zonal advection (hAdv), its dominance becomes clearer with small differences between RAs. Vertical advection also contributes positively to MSE propagation despite relatively large inter-RA spread (about 17\% of the MRM value).

While several studies have found that vertical advection serves as the dominant MSE recharging process to the east of MJO convection (e.g., Chen and Wang 2018), we found that the relative importance of vertical advection becomes comparable to that of horizontal advection only when the analysis was performed on a narrow band near the equator (e.g., $5^{\circ} \mathrm{S}-5^{\circ} \mathrm{N}$, not shown). In this study, instead of focusing on the near-equatorial processes, we analyze MJO MSE budget over the latitude band between $15^{\circ} \mathrm{S}$ and $15^{\circ} \mathrm{N}$ that can account for the full meridional scale of the MJO MSE anomalies (e.g., Fig. 4). LW exhibits notable inter-RA spread (about $34 \%$ of the MRM value). The contribution of LW to MSE propagation in MERRA-2 and JRA-55 is relatively small, which is likely related to the relatively weak cloud-radiation feedback strength (Table 4).

The contribution of the budget residual to MSE propagation is not negligible and it shows substantial inter RA-spread. In CFSR and ERA-I, the budget residual gives relatively large positive contributions to MJO propagation (Fig. 7), which appears to compensate the overly active LH and LW in CFSR and the relatively weak wAdv in ERA-I. Sobel et al. (2014) also showed that the contribution of vertical advection to MJO propagation in ERA-I was underestimated compared to that in the DYNAMO sounding data. In MERRA-2, the negative budget residual suggests that the model is overproducing MSE recharging and discharging associated with MJO MSE propagation, which may be due to the weak contributions from LW.

In the maintenance of the MJO MSE anomalies (Fig. 8b), vertical MSE advection and longwave radiative heating are the two dominant processes in terms of the magnitude. Their dominance in the magnitude over other terms, however, disappears when combined (CONV), suggesting that examining the role of the other terms need to be considered together with CONV. This is especially true given that wAdv and LW tend to be negatively correlated. For example, in the area of enhanced MJO convection, MSE is exported out of the column via vertical MSE advection while anomalous LW partially compensates the loss of MSE. Both terms show notable spread among the RAs, with the standard 

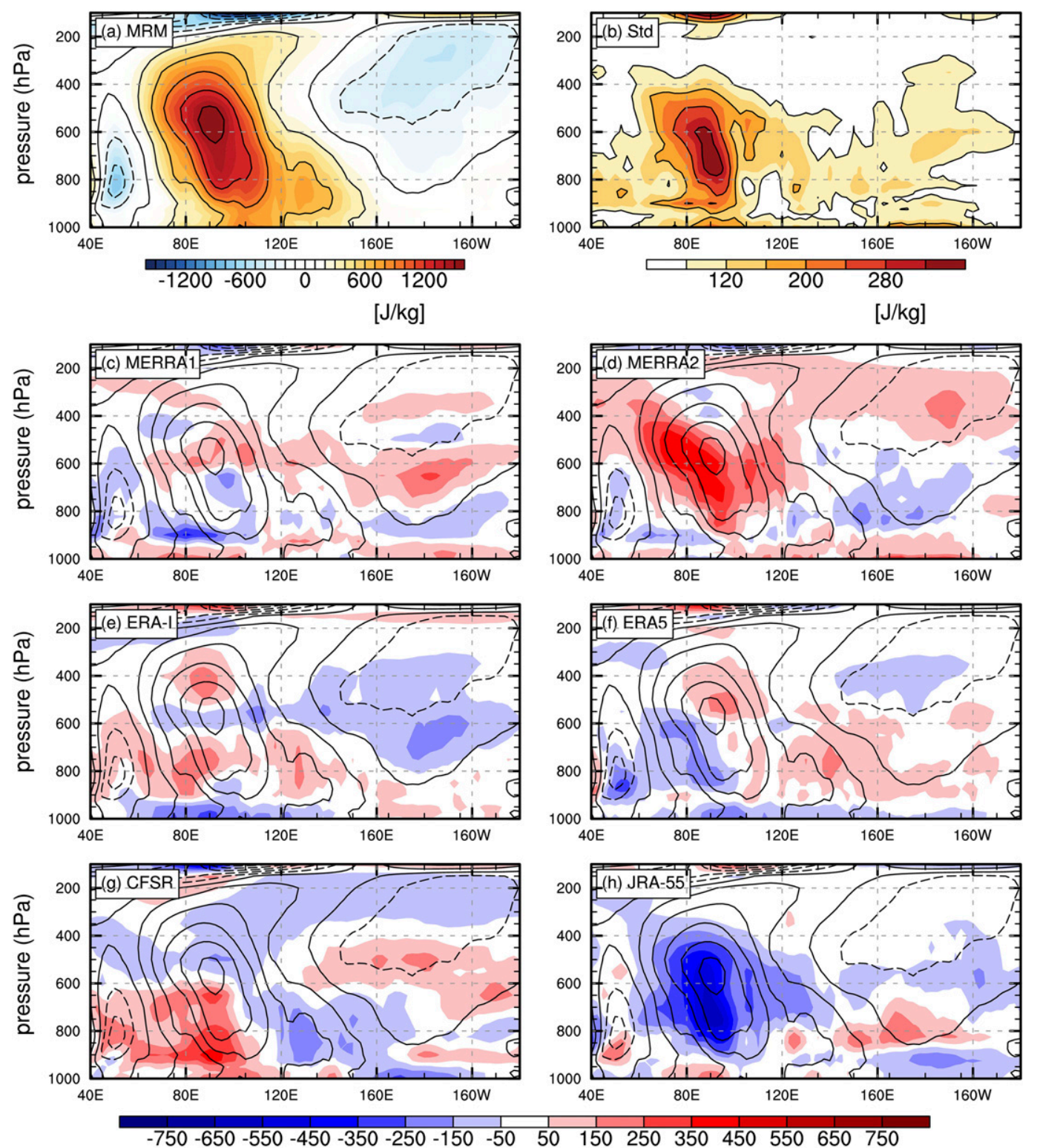

$[\mathrm{J} / \mathrm{kg}]$

FIG. 5. As in Fig. 4, but for longitude-pressure composite of MSE anomaly averaged over $15^{\circ} \mathrm{S}-15^{\circ} \mathrm{N}$. The contour interval is $300 \mathrm{~J} \mathrm{~kg}^{-1}$.

deviation of wAdv and LW being about $25 \%$ and $18 \%$ of its MRM values, respectively. When the two terms are considered together (CONV), the effect of wAdv dominates in most RAs. Horizontal advection contributes negatively to MSE maintenance in all RAs, indicating a damping effect (e.g., Wolding et al. 2016), whereas shortwave radiative heating and surface latent heat flux has a nonnegligible positive contribution to the MSE amplitude. It is worthwhile to mention that Fig. $8 \mathrm{~b}$ is normalized by the variance of MSE anomalies [Eq. (4b)]. The damping effect of wAdv on MSE anomalies is relatively large in JRA-55 partly because its MSE anomalies are relatively small (Fig. 3). The cause of the large inter-RA spread in wAdv will be examined further below.
Interestingly, in all RAs, the budget residual contributes positively to the maintenance of MJO MSE anomalies, indicating the common bias in the models used in RAs of underestimating the amplitude of the MJO. The budget residual plays a particularly important role in MSE maintenance in three RAs: MERRA-1, MERRA-2, and JRA-55. It appears that in these RAs the budget residual is required to compensate the overly active MSE sink from the processes that are directly affected by local convective activity (CONV). In other words, inadequate representations of convection, cloud, and radiation could be mainly responsible for the budget residual around the positive and negative MSE anomaly peaks. For MERRA-1 and 

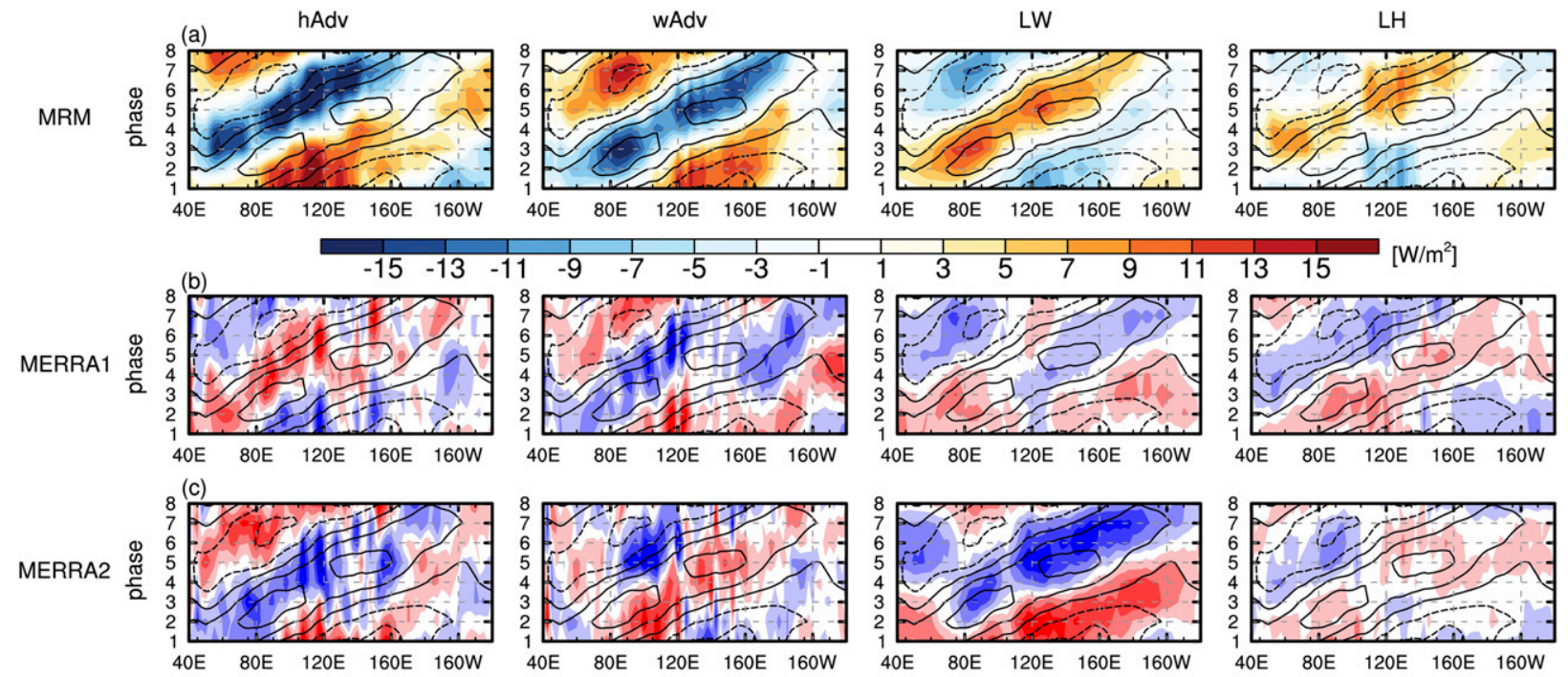

ERA-I
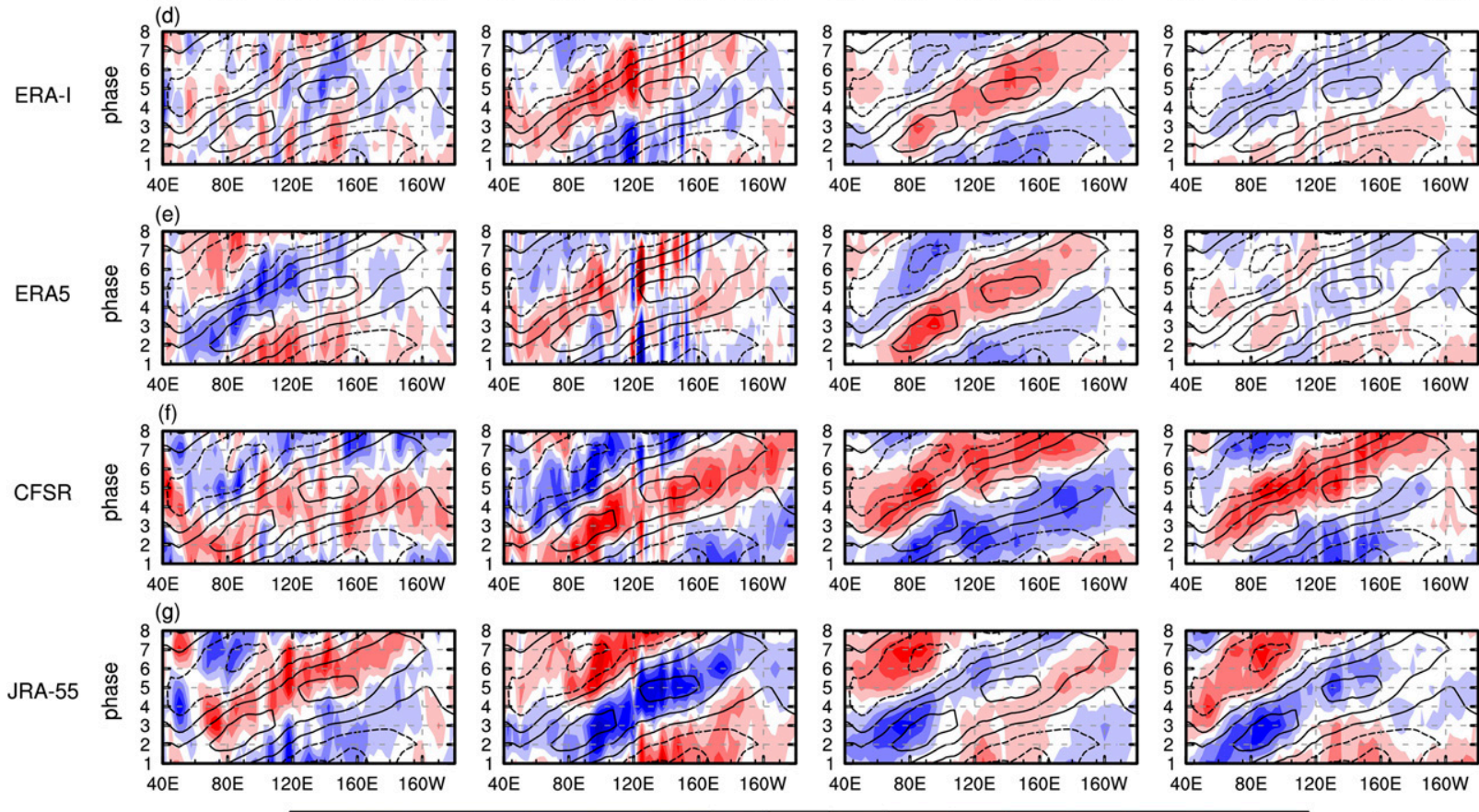

\begin{tabular}{lllllllllllllllll}
\hline & -7.5 & -6.5 & -5.5 & -4.5 & -3.5 & -2.5 & -1.5 & -0.5 & 0.5 & 1.5 & 2.5 & 3.5 & 4.5 & 5.5 & 6.5 & 7.5
\end{tabular}
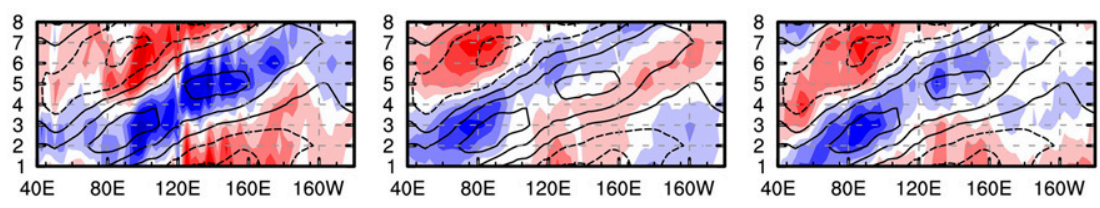

FIG. 6. Longitude-phase composite of (left to right) hAdv, wAdv, LW, and LH, respectively, for (a) the MRM and (b)-(g) the differences MRM for (b) MERRA-1, (c) MERRA-2, (d) ERA-I, (e) ERA5, (f) CFSR, and (g) JRA-55. The contours show the MRM MSE anomalies with the interval of $3 \times 10^{6} \mathrm{~J} \mathrm{~m}^{-2}$.

JRA-55, MSE export by vertical advection is larger than the other RAs, while LW is relatively weak in MERRA-2.

To better understand the inter-RA differences in vertical MSE advection, Figs. 9a and $9 \mathrm{~b}$ show the vertical profiles of the mean MSE and its vertical gradient over the eastern equatorial Indian Ocean, where a relatively large difference is found between RAs in MJO MSE anomalies during MJO phase 3 (black box in Fig. 4a). In the mean MSE, as seen in Fig. 2, substantial differences between the RAs occur in the upper boundary layer $(900-800 \mathrm{hPa}$ ) and below the melting level (700-500 hPa). While ERA-I, ERA5, CFSR, and JRA-55 show the level of minimum MSE at around $650 \mathrm{hPa}$, the minimum MSE appears below $700 \mathrm{hPa}$ in MERRA-1 and MERRA-2. As a result, between 850 and $600 \mathrm{hPa}$, where significant MSE anomalies appear (Fig. 5), the mean MSE vertical gradient is larger in JRA-55 and ERA5 than in MERRA-1 and MERRA-2.

The anomalous vertical motion during MJO phase 3 over EIO exhibits considerable inter-RA differences in their magnitude, especially in the layer between 600 and $200 \mathrm{hPa}$ (Fig. 9c). Note that the vertical motion anomalies shown in Fig. 9c are normalized by column MSE anomalies. JRA-55, which shows a relatively 

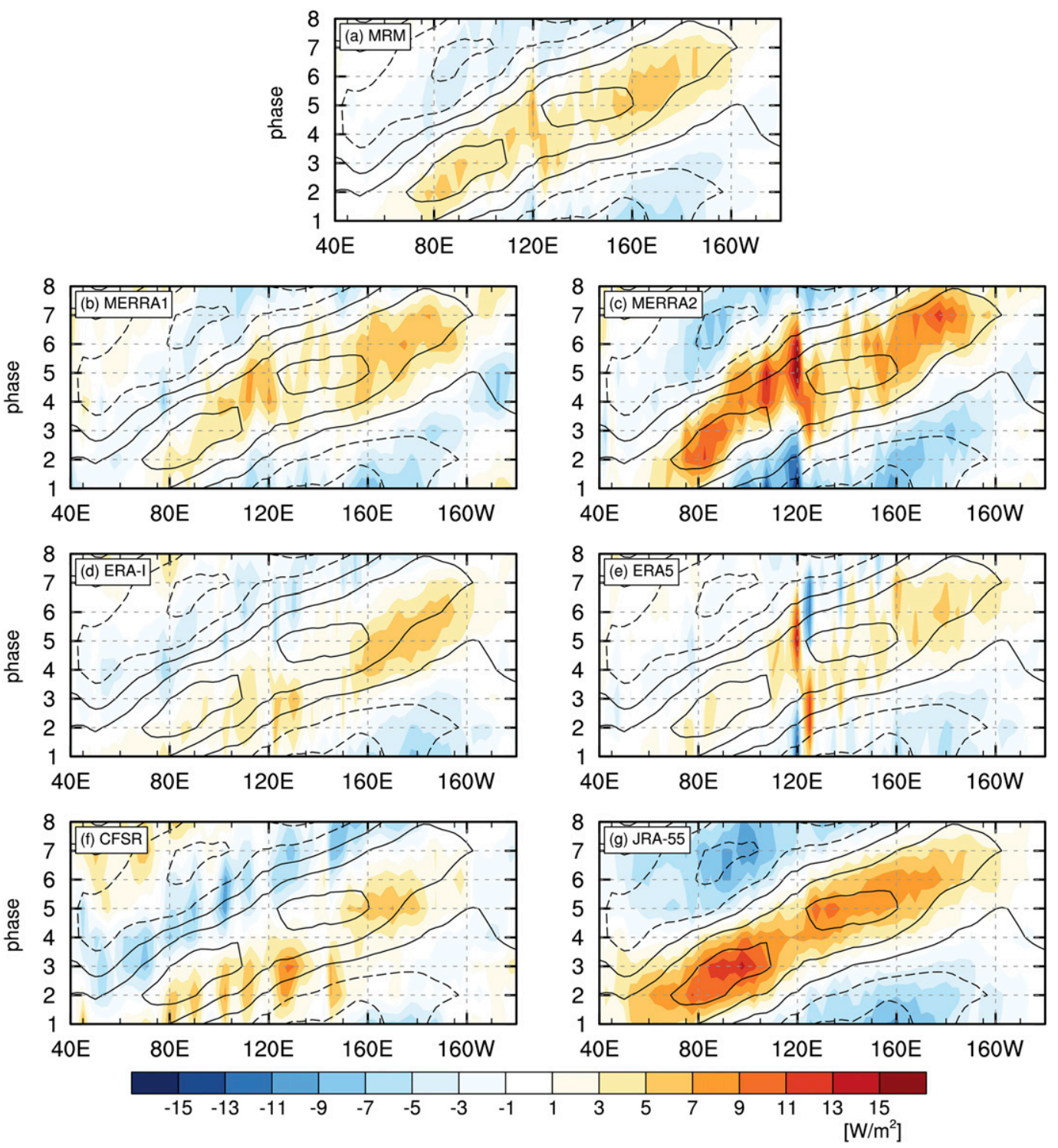

FIG. 7. Longitude-phase composites of MSE budget residual for (a) MRM, (b) MERRA-1, (c) MERRA-2, (d) ERA-I, (e) ERA5, (f) CFSR, and (g) JRA-55. The contours show the MRM MSE anomalies with the interval of $3 \times 10^{6} \mathrm{~J} \mathrm{~m}^{-2}$.

large vertical velocity, has relatively small MSE anomalies (Table 3). The RAs with stronger anomalous vertical motion also exhibit stronger apparent heating (Fig. 9d), suggesting that the uncertainty in the forecast model diabatic processes is responsible for the inter-RA difference in anomalous vertical motion.

Figure 9e shows the vertical profiles of anomalous vertical MSE advection that is approximated by the advection of mean MSE by anomalous vertical motion. It can be inferred from Fig. 9e that the column-integrated vertical MSE advection is dominated by the negative MSE advection in the upper troposphere above around $600 \mathrm{hPa}$, which the result of the anomalous upward motion acting upon the mean negative MSE gradient. The magnitude of vertical MSE advection differs considerably among RAs, which is mainly due to the differences in vertical velocity. The negative vertical MSE advection above the level of minimum mean MSE is partly offset by the positive MSE vertical advection below, yielding a net MSE export in all RAs (Table 3). In JRA-55, both positive and negative MSE advections are relatively large due to the relatively stronger normalized ascent (Fig. 9e). The normalized net MSE export by vertical advection (third row in Table 3) is also largest in JRA-55, which is consistent with the largest MSE damping effect from vertical advection (Fig. 8b). In contrast, the vertical MSE advection above the minimum MSE level is weaker in CFSR and MERRA-2, yielding a smaller normalized net MSE export (Table 3). In Fig. 8b, these two RAs show relatively weaker damping effect from vertical MSE advection. The results shown in Fig. 9 and Table 3 suggest the substantial inter-RA differences in vertical 

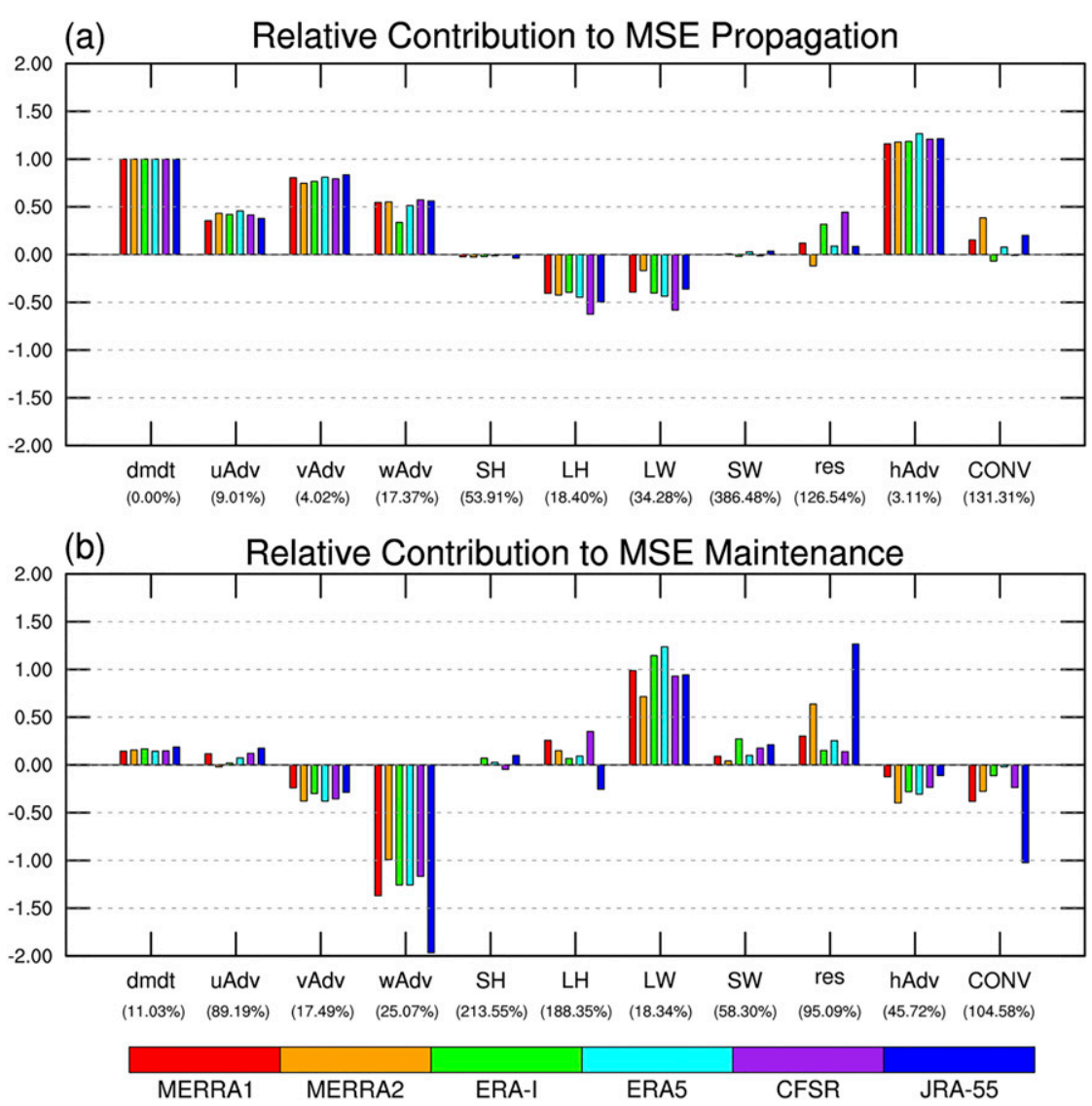

FIG. 8. Normalized contribution of the individual terms in the column-integrated MSE budget to the (a) propagation and (b) maintenance of MJO MSE anomalies over the domain $15^{\circ} \mathrm{S}-15^{\circ} \mathrm{N}$, $60^{\circ} \mathrm{E}-180^{\circ}$, and $\mathrm{MJO}$ phases $1-8$. The value for each bar is obtained using Eq. (4). The individual budget terms shown include, from left to right, MSE tendency (dmdt), zonal MSE advection (uAdv), meridional MSE advection (vAdv), vertical MSE advection (wAdv), surface sensible heat fluxes $(\mathrm{SH})$, surface latent heat fluxes $(\mathrm{LH})$, column longwave radiative heating $(\mathrm{LW})$, column shortwave radiative heating (SW), the budget residual (res), the sum of zonal MSE advection and meridional MSE advection (hAdv), and the sum of longwave heating and vertical MSE advection (CONV). The numbers in parentheses indicate a measure of the inter-RA spread, which is obtained for each budget term by dividing the standard deviation of values from six RAs by the absolute value of its corresponding MRM value. The resulting number is shown as a percentage.

MSE advection is due to the differing representation of anomalous vertical motion associated with the MJO among the RAs.

\section{Relationship between cloud-radiation feedback, convective moisture adjustment time scale, and CWV budget residual}

Yokoi (2015) performed an MJO CWV budget analysis using three RAs (JRA-25, JRA-55, and ERA-I) and Special Sensor Microwave Imager (SSM/I) observations. Under the WTG approximation and other assumptions, the following equation was obtained in Yokoi (2015):

$$
\frac{\hat{I}}{\hat{P}} \propto(\tilde{M}-1)\left(r-r_{r}\right)
$$

where $I$ is analysis increment, $\tilde{M}$ represents the normalized gross moist stability (NGMS), $r$ and $r_{r}$ are the cloud-radiation feedback strength in the forecast model and real atmosphere, respectively. The cloud-radiation feedback strength is estimated as the ratio of anomalous OLR (a proxy of column longwave heating) to precipitation (a proxy of column condensational heating) anomalies (fifth column in Table 4):

$$
\frac{r \equiv-\widehat{\mathrm{OLR}}}{L_{v} \hat{P}}
$$

In Eqs. (5) and (6), the hatted variables $(\hat{I}, \hat{P}$, and $\widehat{\mathrm{OLR}})$ are the regression coefficients that are obtained by regressing the MJO composite of each variable against the corresponding CWV anomalies over the warm pool region $\left(15^{\circ} \mathrm{S}-15^{\circ} \mathrm{N}, 60^{\circ} \mathrm{E}-180^{\circ}\right)$ and for MJO phases $1-8$. 
(a)

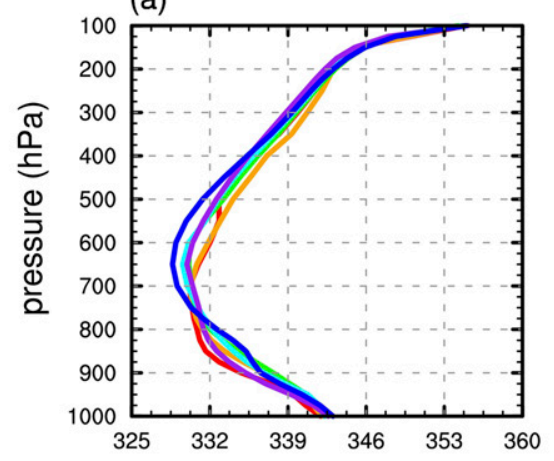

(b)

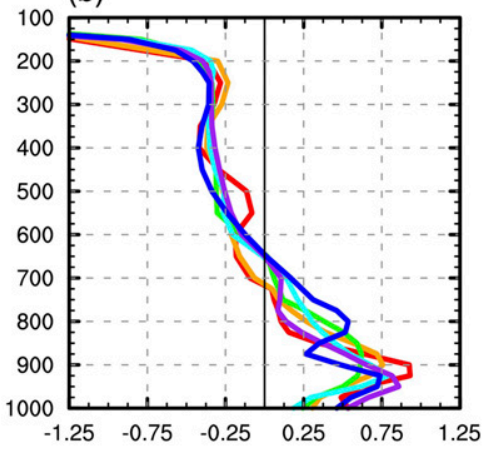

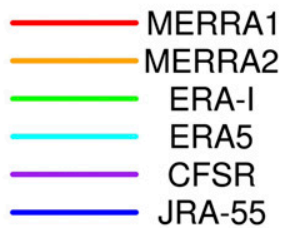

(c)

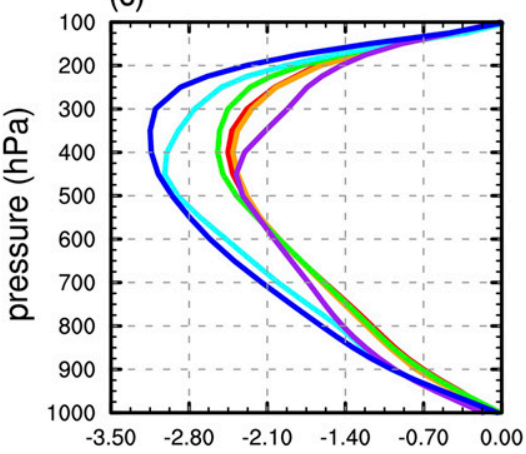

(d)

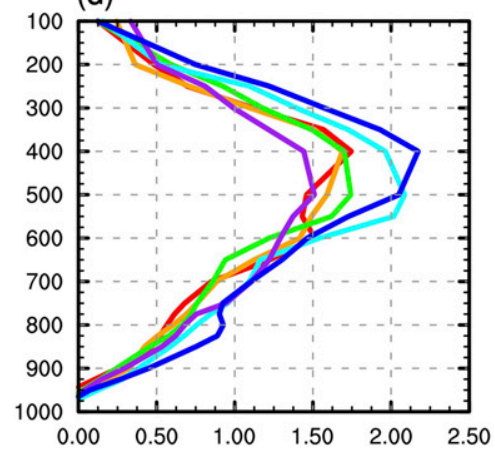

(e)

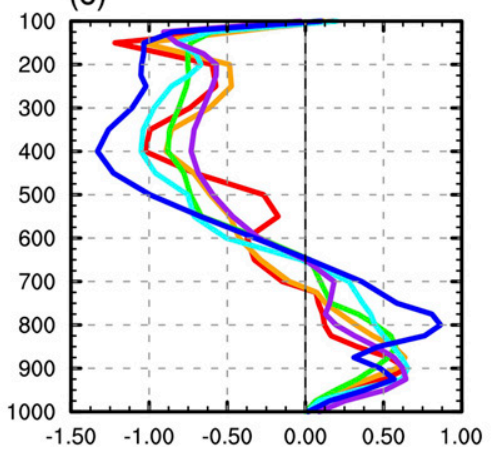

FIG. 9. Vertical profile of (a) the mean MSE $\left(\mathrm{kJ} \mathrm{kg}^{-1}\right)$ and (b) its vertical gradient $\left(\mathrm{J} \mathrm{kg}^{-1} \mathrm{~Pa}^{-1}\right)$ averaged over the domain of $16^{\circ}-4^{\circ} \mathrm{S}$, $87.5^{\circ}-107.5^{\circ} \mathrm{E}$ (box in Fig. 4a). (c)-(e) As in (a), but for (c) anomalous vertical velocity ( $\mathrm{Pa} \mathrm{s}^{-1}$ ), (d) apparent heating $\left(Q_{1}\right)$, and (e) advection of mean MSE by anomalous vertical motion $\left(\mathrm{W} \mathrm{kg}^{-1}\right)$. The quantities plotted in (c)-(e) are normalized by the corresponding column-integrated MSE anomalies.

Based on Eq. (5), a hypothesis was proposed by Yokoi (2015): if NGMS is similar across the RAs, the bias in the cloud-radiation feedback strength $\left(r-r_{r}\right)$ would exhibit a linear relationship with the ratio of CWV analysis increment to precipitation anomalies $(\hat{I} / \hat{P})$. He found a nearly perfect linear relationship between the two quantities (see their Fig. 6), which strongly supported the hypothesis. In the following, we extend Yokoi's (2015) analysis by using more RAs - two RAs used by Yokoi (2015) plus four additional RAs - and by investigating the relationship of CVW budget residual with other quantities.

We first test one of the key assumptions made in the derivation of Eq. (5): the balance between precipitation and

TABLE 3. Column-integrated vertical MSE advection, MSE anomalies, and vertical MSE advection normalized by MSE anomalies over the eastern Indian Ocean (the black solid line box in Fig. 4a) during MJO phase 3. Note that vertical MSE advection is approximately estimated by the advection of mean MSE by anomalous vertical motion.

\begin{tabular}{lcrc}
\hline \hline & wAdv & MSE & wAdv/MSE \\
\hline MERRA-1 & -25.10 & 9.08 & -2.76 \\
MERRA-2 & -25.93 & 10.49 & -2.47 \\
ERA-I & -26.82 & 9.63 & -2.79 \\
ERA5 & -26.89 & 9.29 & -2.89 \\
CFSv2 & -19.49 & 9.05 & -2.15 \\
JRA-55 & -26.04 & 7.51 & -3.47 \\
\hline
\end{tabular}

vertical moisture advection is mainly responsible for the budget residual among the other budget terms. The relationship of the CWV budget residual with the other CWV budget terms (Fig. 10) shows that the ratio of vertical moisture advection to precipitation is most strongly associated with the budget residual normalized by precipitation (corr $=-0.96$, Fig. 10c), suggesting its major role in causing $\mathrm{CWV}$ budget residual. However, it is unlikely that vertical moisture advection is the only process that is responsible for the CWV budget residual, as the zonal advection term is also tightly correlated with the CWV budget residual (Fig. 10a), though the correlation is not statistically significant at the $95 \%$ confidence level.

TABLE 4. Regressed composite anomalies of (second column) budget residual, (third column) precipitation, and (fourth column) OLR variables against composite CWV anomaly calculated over $60^{\circ} \mathrm{E}-180^{\circ}$ and $\mathrm{MJO}$ phases $1-8$. The cloud-radiation feedback strength $r$ and the convective adjustment time scale $\tau_{c}$ are shown in the fifth and sixth columns, respectively.

\begin{tabular}{lccccc}
\hline \hline & $\hat{I}$ & $L_{v} \hat{P}$ & $\widehat{\mathrm{OLR}}$ & $r$ & $\tau_{c}$ \\
\hline MERRA-1 & 0.024 & 18.74 & -4.55 & 0.24 & 1.54 \\
MERRA-2 & 0.115 & 23.07 & -3.48 & 0.15 & 1.25 \\
ERA-I & -0.06 & 15.67 & -5.03 & 0.32 & 1.85 \\
ERA5 & 0.003 & 21.54 & -5.42 & 0.25 & 1.34 \\
CFSv2 & 0.019 & 19.99 & -4.45 & 0.22 & 1.45 \\
JRA-55 & 0.074 & 23.52 & -4.56 & 0.18 & 1.14 \\
\hline
\end{tabular}


(a)

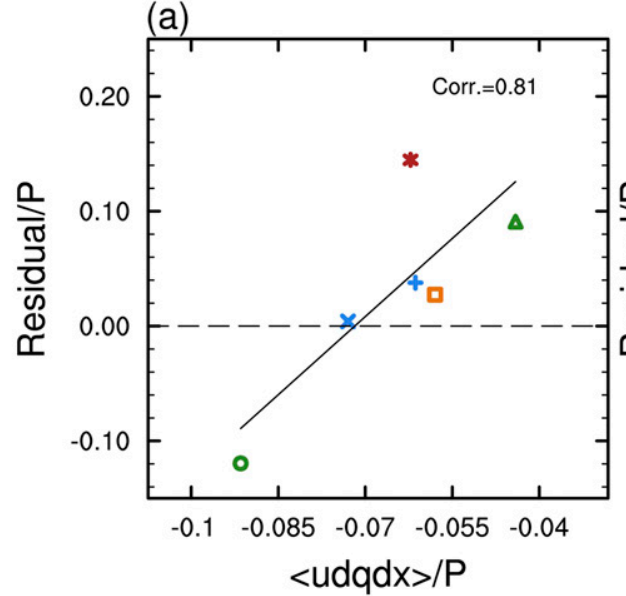

(c)

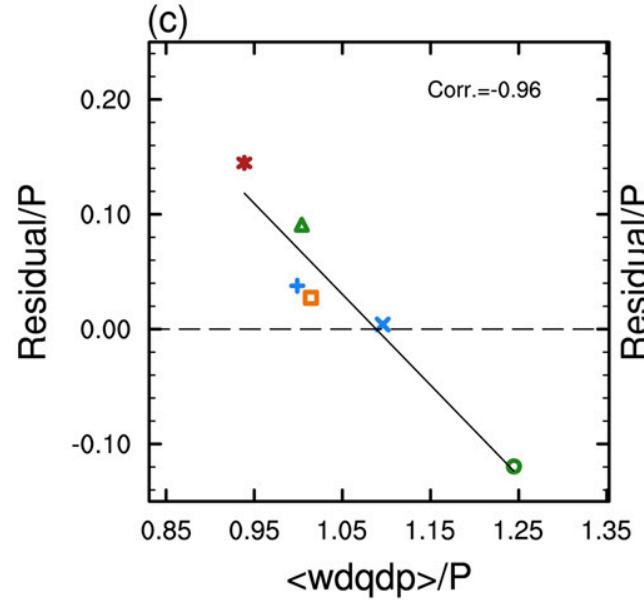

MERRA1

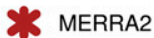

MERRA2

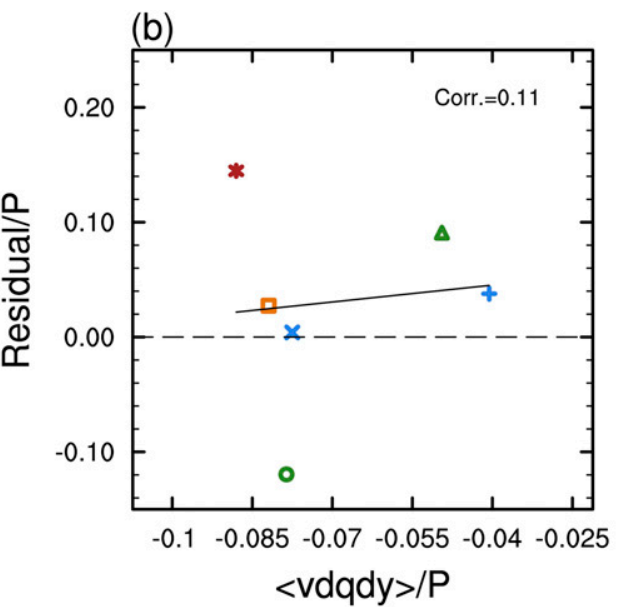

(d)

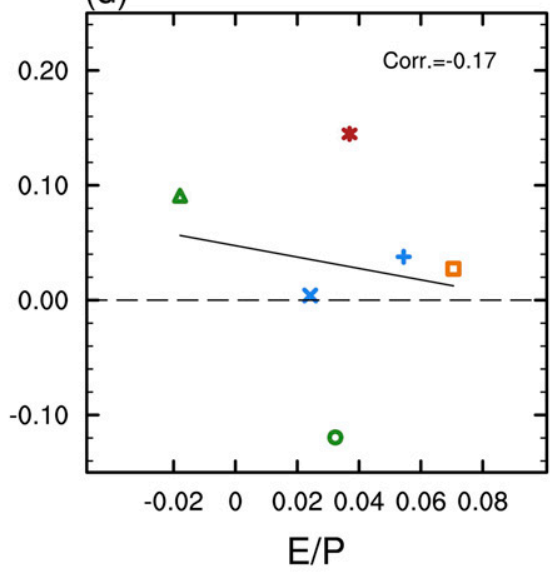

ERA5

A JRA-55

FIG. 10. Scatterplot of the normalized CWV budget residual with the normalized (a) zonal advection, (b) meridional advection, (c) vertical advection, and (d) surface latent heat flux. The quantities are obtained through regressions using values over the warm pool $\left(15^{\circ} \mathrm{S}-15^{\circ} \mathrm{N}, 60^{\circ} \mathrm{E}-180^{\circ}\right)$ and for MJO phases $1-8$ (see text).

In Yokoi (2015), the ratio of vertical moisture advection to precipitation was represented as a function of NGMS, and $r$ :

$$
\left\langle w \frac{\partial q}{\partial z}\right\rangle^{\prime} / P^{\prime} \cong(1-\tilde{M})(1+r)
$$

We find a high linear correlation between $r$ and the ratio of vertical advection to precipitation (Fig. 11a), which indicates the major role of cloud-radiation feedbacks in determining the balance between vertical advection and precipitation. Despite the caveats of the constant NGMS assumption (Yokoi 2015), our result suggests that the RHS in Eq. (7) is more strongly affected by changes in $r$ than in NGMS (Fig. 11b). A similar conclusion is drawn from the limited period during the DYNAMO field campaign (appendix). It is worthwhile to note, however, that the positive linear correlation between $r$ and the normalized vertical moisture advection could also indicate that a larger $r$ is a result, not the cause, of larger vertical moisture advection. That is, a greater amount of vertical moisture transport per unit precipitation can lead to larger moisture and cloud fraction anomalies in the column, which would decrease OLR and increase $r$. Revealing the causality in the relationship between the two processes warrants further studies.

The vertical moisture advection term can also be represented in terms of apparent heating $\left(Q_{1}\right)$ and the "Chikira parameter"' $\alpha$ (Chikira 2014):

$$
\left\langle w \frac{\partial q}{\partial z}\right\rangle^{\prime} / P^{\prime} \cong-\frac{1}{L_{v}}\left\langle\alpha Q_{1}\right\rangle^{\prime} / P^{\prime} .
$$

where $\alpha \equiv-L_{v}(\partial q / \partial p)(\partial s / \partial p)^{-1}$. Under the WTG approximation, the Chikira parameter represents the efficiency of moistening by vertical motion associated with apparent heating. A larger $\alpha$ would mean a greater moistening per given apparent heating. Motivated by the success of Eq. (8) in disentangling the role of 
(a)

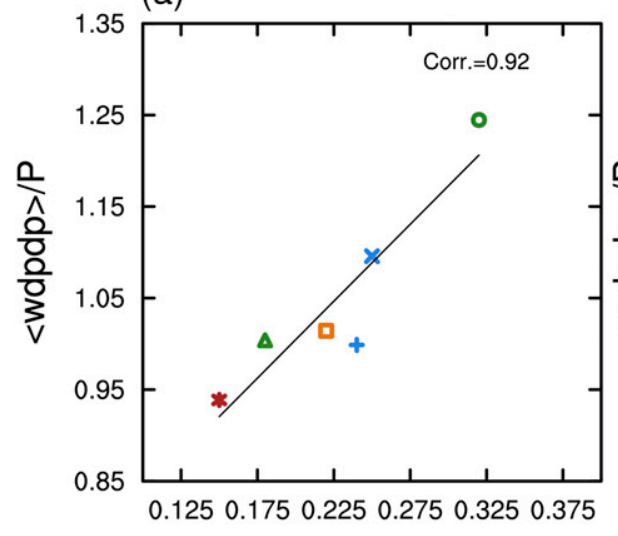

$r$

(c)

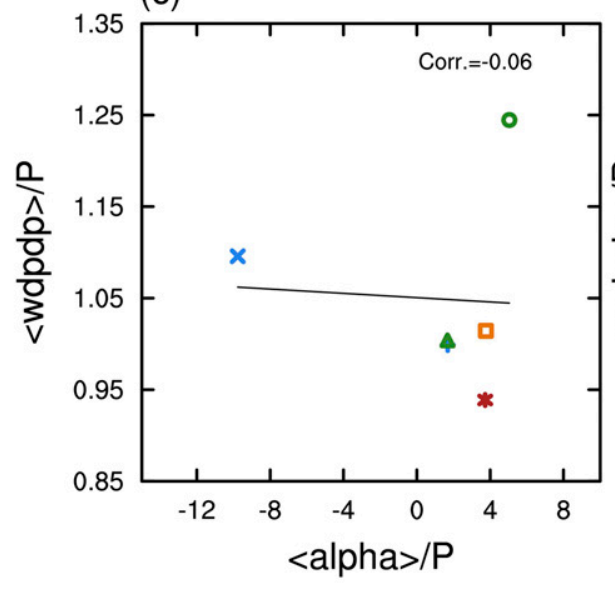

(b)

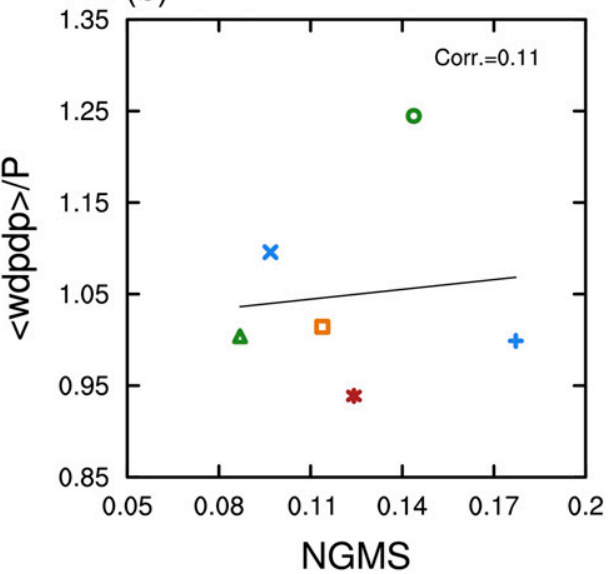

(d)

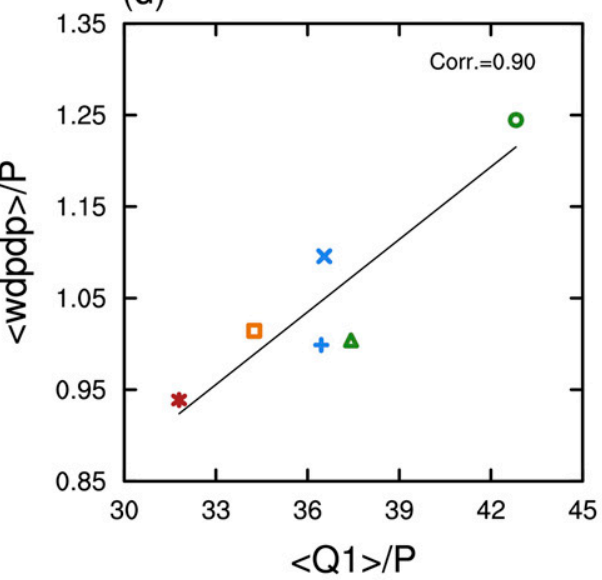

MERRA1

MERRA2

ERA-I

XRA5

CFSR

A JRA-55

FIG. 11. Scatterplot of the ratio of vertical moisture advection to precipitation with (a) the cloud-radiation feedback strength $(r)$, (b) the normalized gross moist stability, (c) alpha normalized by precipitation, and (d) apparent heating normalized by precipitation. The quantities are obtained through regressions using values over the warm pool $\left(15^{\circ} \mathrm{S}-15^{\circ} \mathrm{N}, 60^{\circ} \mathrm{E}-180^{\circ}\right)$ and for MJO phases $1-8$ (see text).

moisture gradient and apparent heating in recent studies (Wolding et al. 2016, 2017; Bui and Maloney 2018), we examined whether column-integrated $\alpha$ or apparent heating is systematically associated with CWV budget residual in RAs. It is found that the ratio of vertical moisture advection to precipitation is largely controlled by that of apparent heating (Fig. 11d), while $\alpha$ does not show a linear relationship with the magnitude of vertical moisture advection (Fig. 11c). Therefore, in both column MSE and CWV budgets, the inter-RA spread in vertical advection mainly comes from that in apparent heating and vertical motion it induces.

Figure 12a shows that the strength of cloud-radiation feedback quantified with $r$ varies widely among the RAs (ERA-I is greater than MERRA-2 by a factor of 2), implying that the process is poorly constrained in RAs. Nonetheless, a nearly linear relationship between $r$ and $\hat{I} / \hat{P}$ is found, which is almost identical to what Yokoi (2015) showed. Table 4 shows the values of $\hat{I}$ and $\hat{P}$ (second and third columns). Note that, unlike Yokoi
(2015), who used the analysis increment in his examination, we use the budget residual as an estimate of the analysis increment. JRA-55 and ERA-I results are consistent with Yokoi's (2015) quantitatively, suggesting that it is reasonable to approximate analysis increment by the budget residual.

According to Yokoi's (2015) interpretation of the negative linear relationship between $r$ and $\hat{I} / \hat{P}, \hat{I} / \hat{P}$ is positive because moisture anomalies are weakly reinforced by cloud-radiation feedbacks; for example, an overestimated $r$ in an RA would causes $\hat{I} / \hat{P}$ to be negative (ERA-I). In an anomalously moist column, precipitation and vertical moisture advection are typically the dominant sink and source terms of moisture, respectively. The positive moisture anomaly would grow or decay depending on how moisture sink and source terms are balanced in the column. Under the WTG gradient approximation, anomalous upward motion is induced by anomalous apparent heating (Sobel et al. 2001). Although a large fraction of anomalous apparent heating comes from net condensation in the 
(a)

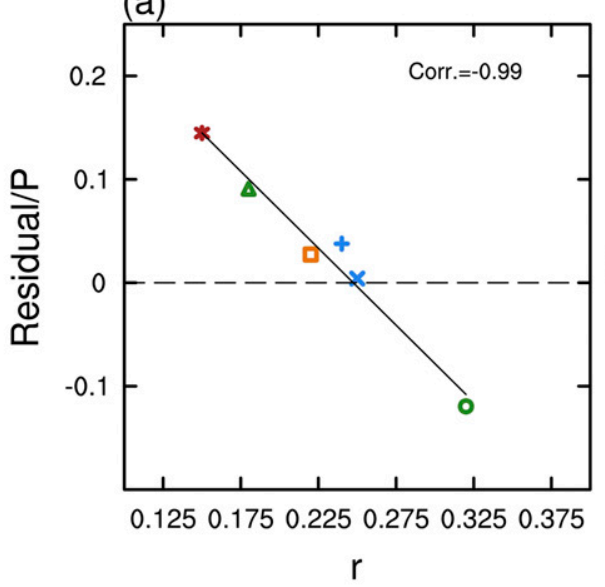

(c)

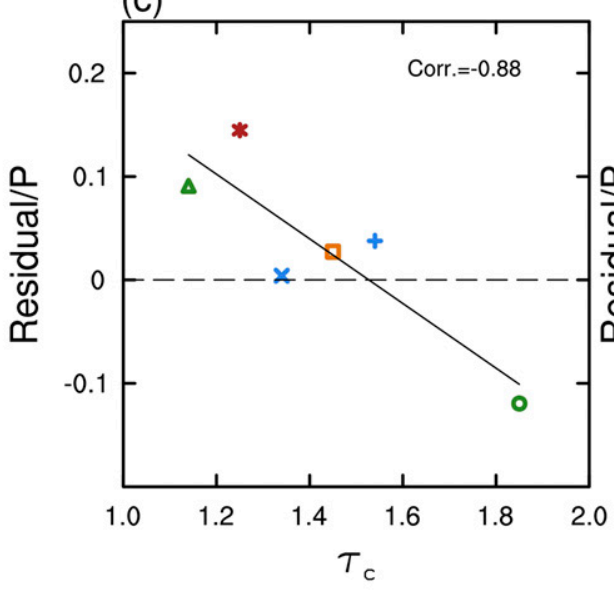

MERRA1

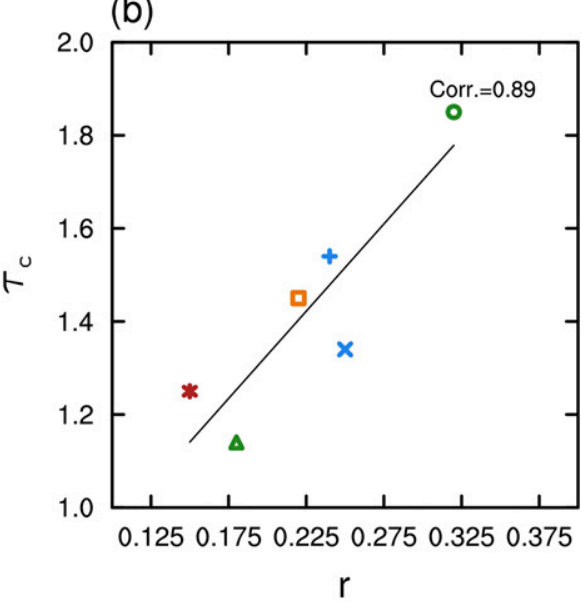

(d)

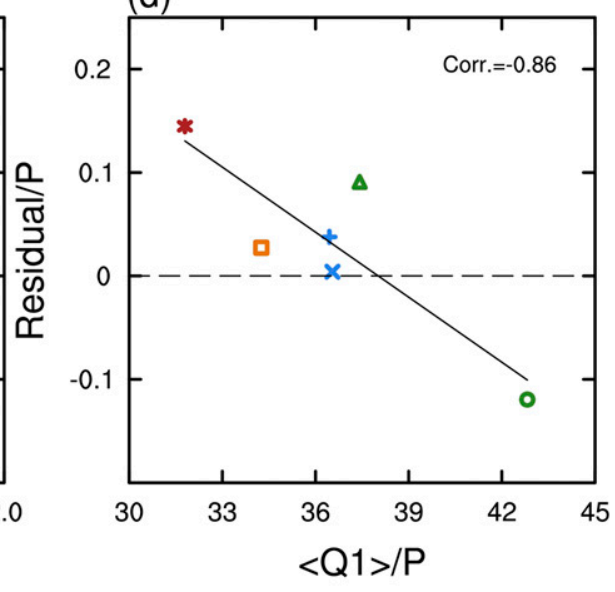

FIG. 12. Scatterplot of the normalized CWV budget residual with (a) the cloud-radiation feedback strength $(r)$, (c) the convective moisture adjustment time scale $\left(\tau_{c}\right)$, and (d) column-integrated apparent heating normalized by precipitation. (b) Scatterplot between $r$ and $\tau_{c}$. The quantities are obtained through regressions using values over the warm pool $\left(15^{\circ} \mathrm{S}-15^{\circ} \mathrm{N}, 60^{\circ} \mathrm{E}-180^{\circ}\right)$ and for MJO phases $1-8$ (see text).

column, column net condensation (i.e., precipitation) also serves as the dominant moisture sink. Anomalous radiative heating, on the other hand, acts to increase moisture by inducing vertical motion without corresponding moisture sink. Therefore, if longwave radiative heating is underestimated for the same amount of precipitation (lower $r$ ), the column has a greater chance to become drier than what it is supposed to be (e.g., the observed state). The data assimilation system then would add moisture to compensate for the dry bias. The sum of precipitation and vertical moisture advection shown in Fig. 13 (right panels) exhibits a greater net moistening in ERA-I and a net drying in MERRA-2 and JRA-55, consistent with their large negative (ERA-I) and positive (MERRA-2 and JRA55) budget residual. A peculiar feature in MERRA-2 is that its moisture analysis increment (estimated by budget residual) is positive and largest even though CWV anomalies are larger than those in the other RAs, suggesting that data assimilation scheme maybe overcompensate moisture deficit from the net effect of precipitation and vertical moisture advection.

In Eq. (6), $r$ consists of two factors: $\widehat{\text { OLR }}$ and $\hat{P}$. The factor $\hat{P}$ has the unit of day ${ }^{-1}$ and can be related to a measure of convective moisture adjustment time scale (e.g., Jiang et al. 2016):

$$
\tau_{c} \equiv \frac{1}{\hat{P}}
$$

A longer $\tau_{c}$ means the ratio of precipitation to CWV anomaly is smaller; therefore, it would take a longer time for precipitation to remove the moisture anomaly. By substituting Eq. (9) into Eq. (6), we obtain:

$$
\frac{r=-\widehat{\mathrm{OLR}}}{L_{v} \tau_{c},}
$$


(a)

MRM

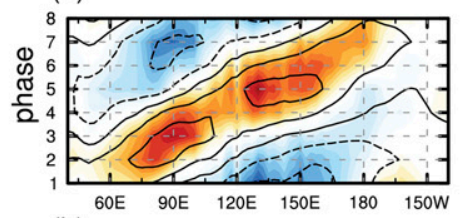

(b)

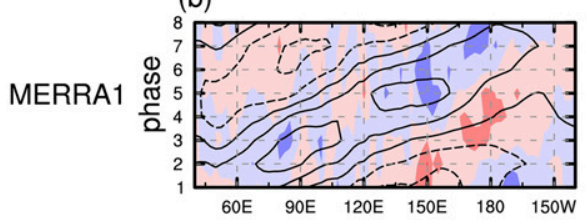
(c)
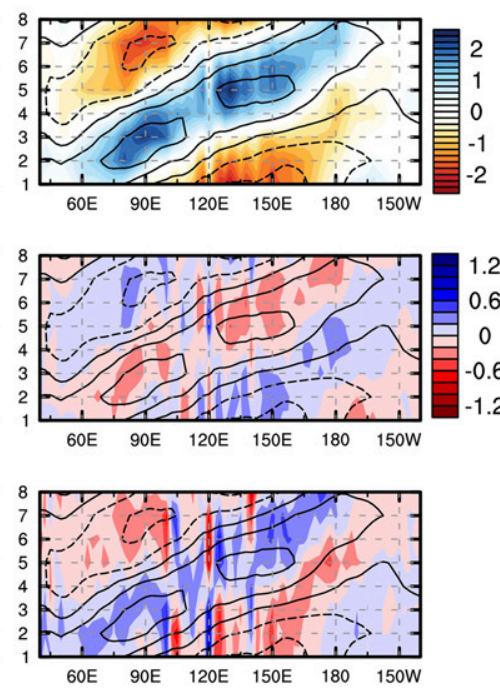

(d)
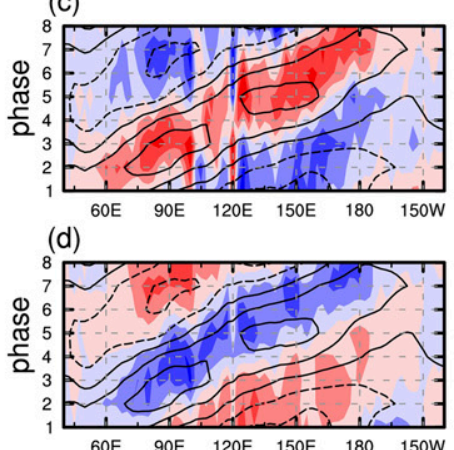

(e)
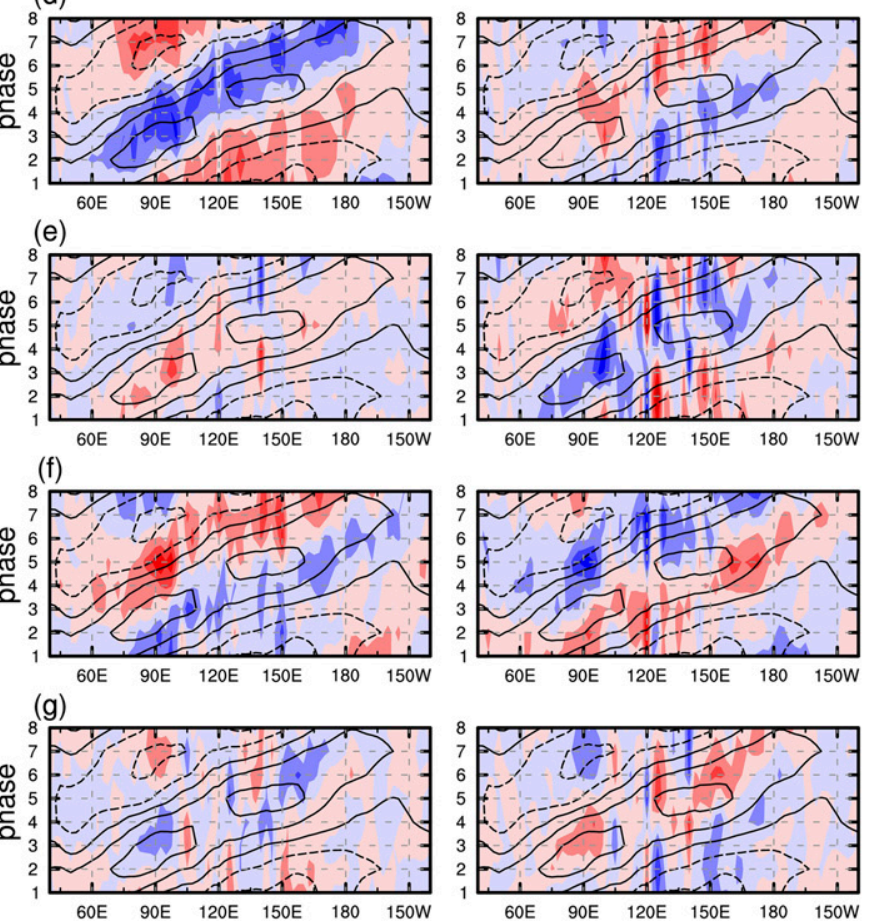
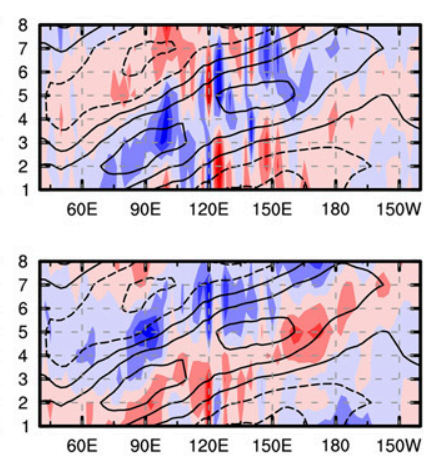

(g)

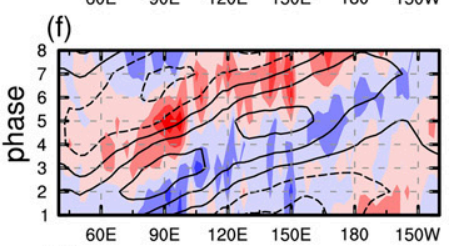

CFSR

JRA-55

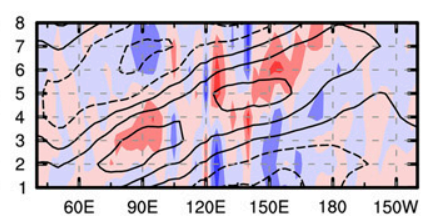

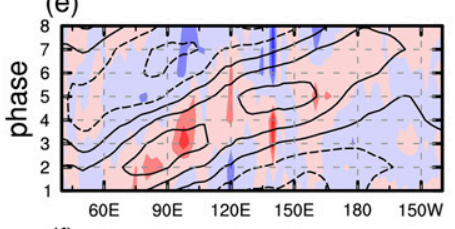
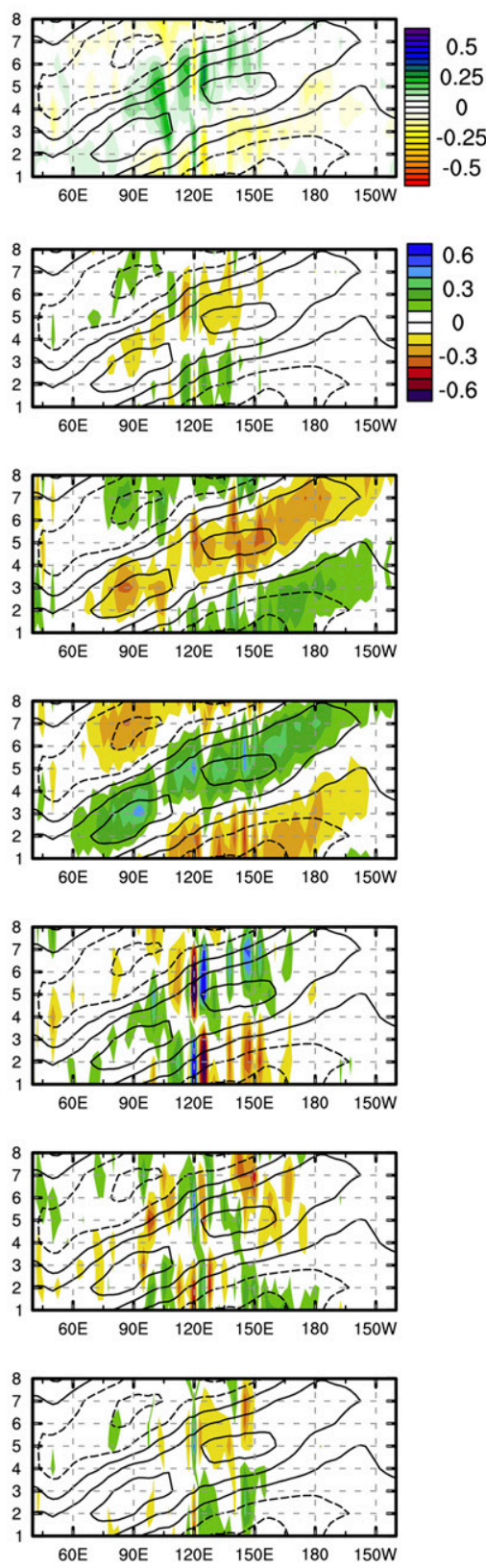

FIG. 13. (a) Longitude-phase composites of MRM (left) precipitation (multiplied by -1), (center) vertical moisture advection, and (right) sum of the two terms. (b)-(g) Differences from MRM for (b) MERRA-1, (c) MERRA-2, (d) ERA-I, (e) ERA5, (f) CFSR, and (g) JRA-55. The contours show the MRM MSE anomalies with the interval of $3 \times 10^{6} \mathrm{~J} \mathrm{~m}^{-2}$.

which indicates that the strength of cloud-radiation feedback is proportional to the convective adjustment time scale. Following the water budget argument above, a stronger $r$ and greater vertical moisture advection would lead moisture anomalies to be greater for a given precipitation anomaly, hence a greater $\tau_{c}$. In fact, $r$ and $\tau_{c}$ are positively correlated among the six RAs (Fig. 12b), and, not surprisingly, a negative linear relationship exists between $\tau_{c}$ and $\hat{I} / \hat{P}$ (corr $=0.88$, Fig. 12c). The two factors in Eq. (8) affect $r$ differently in different RAs. For MERRA-2, $r$ is lower than the other
RA because both $\widehat{\mathrm{OLR}}$ and $\tau_{c}$ are lower (Table 4). On the contrary, it is $\tau_{c}$ that makes $r$ for JRA-55 relatively low. ERA-I $r$ is exceptionally higher mainly due to its higher $\tau_{c}$. Column-integrated apparent heating normalized by precipitation also exhibits a strong linear relationship with $\hat{I} / \hat{P}$ (Fig. 12d).

The strong correlation between the budget residual and various process-oriented metrics (Figs. 12a,c,d and 10c) provides an emergent constraint on the metrics and thereby offers the target against which the models used in the construction of RAs can be 
tuned. For example, the observed cloud-radiation feedback strength that can be inferred from Fig. 12a (by taking residual equal to zero) is about 0.25 , which is very close to the value obtained from observations (0.24) by Yokoi (2015). Similarly, the observed $\tau_{c}$ inferred from Fig. $12 \mathrm{c}$ is about 1.53 days, which is close to what was obtained in previous studies (e.g., Jiang et al. 2016). Unlike $r$ and $\tau_{c}$, quantifying vertical moisture advection or apparent heating over large domain and for a long time is not feasible, and the vertical profiles of moisture and vertical velocity in heavily precipitation areas are not well constrained by the state-of-the-art data assimilation techniques. Figure 10c indicates that anomalous column-integrated vertical moisture advection is about 1.1 times larger than precipitation anomalies when the entire MJO life cycle is considered over the warm pool region. While ERA5 is near the inferred target value, the other five RAs are either too large (ERAI) or too small (MERRA-1, MERRA-2, CFSR, and JRA-55). Our results also strongly suggest that, for reducing CWV budget residual in RAs, hence enhancing their quality, the errors in $r, \tau_{c}, Q_{1}$, and vertical moisture advection need to be reduced. Examining the effects of model parameterization schemes, including the convection, cloud, and radiation schemes, and aspects of the data assimilation system on these parameters may help improve the representation of those parameters.

\section{Summary and conclusions}

Recently, the diagnosis of column-integrated moist static energy (MSE) and column water vapor (CWV) budget has been performed in many studies of the MJO (Table 1). The global reanalysis products have provided unique reference datasets against which model simulations can be evaluated. While it has been recognized and documented that nonnegligible differences exist between reanalyses (RAs) in their representations of the MJO MSE or CWV budget, no detailed examinations of the budget have been conducted using more than a few RAs.

In this study, we analyzed and compared the MJO MSE and CWV budget as well as the relevant mean state in six modern RAs: MERRA-1, MERRA-2, ERA-I, ERA5, CFSR, and JRA-55. One of the main purposes of the current study is to document how similarly or differently the processes that are key to MJO propagation and maintenance are represented in the RAs. Special attention was given to the processes that are directly affected by model parameterization schemes of moist physics and also the budget residual, to which the analysis increment is believed to have large contributions.

Notable inter-RA differences were found in the horizontal and vertical gradient of the mean MSE, which affects the MSE budget through the corresponding advection terms. The differences between RAs in the mean MSE are mostly due to those in the mean latent energy (moisture). The horizontal gradient of the mean column-integrated MSE over the Indo-Pacific warm pool was relatively large in MERRA-2 and small in JRA-55. In the vertical structure of the mean MSE, considerable differences between RAs appeared in two layers: the upper planetary boundary layer and lower free troposphere $(950-800 \mathrm{hPa})$ and in the midtroposphere $(700-400 \mathrm{hPa})$. In the layer between 950 and $800 \mathrm{hPa}$, JRA-55 and ERA-I were found to be relatively wet, while MERRA-1 and CFSR were relatively dry. At around
$600 \mathrm{hPa}$, MERRA-2 and JRA-55 were about $20 \%$ wetter and drier than the multireanalysis mean (MRM), respectively.

Column-integrated MSE anomalies associated with the MJO exhibited largest inter-RA spread in the eastern Indian Ocean, where the spread measured by standard deviation is more than $10 \%$ of the MRM value during MJO phases 3 and 7 . The inter-RA spread came mostly from MERRA-2 and JRA55, in which MJO MSE anomalies are relatively large and small, respectively, especially in the mid-to-low troposphere (400$800 \mathrm{hPa}$ ). In CFSR, MSE anomalies below $600 \mathrm{hPa}$ tended to lag those of MRM over the MC, with maximum deviation from MRM occurring 1 phase after the MRM maximum.

The inter-RA spread was found to be greater in the individual MSE budget terms than in the MSE anomalies. In particular, the terms that are directly associated with the model parameterizations schemes, such as vertical advection, column longwave heating, and surface latent heat flux, showed particularly large inter-RA spread. The budget residual plays nonnegligible role in the MJO MSE budget. In MERRA-1, MERRA-2, ERA5, and JRA-55, the budget residual contributes to maintaining the MJO MSE anomalies. In ERA-I and CFSR, on the other hand, it mainly contributes to the recharging and discharging of MSE anomalies to the east and west of positive MSE anomalies, respectively.

In all RAs, horizontal MSE advection is found to be the dominant process for the propagation of MSE anomalies, confirming the result of many previous studies. The quantified relative contribution to MSE propagation of meridional advection was found to be most robust. Vertical MSE advection also contributes positively to the eastward movement of MSE anomalies though it is of secondary importance outside a narrow band near the equator. Surface latent heat flux and longwave radiative heating anomalies slow down the eastward propagation of the MJO MSE anomalies, among which longwave radiative heating exhibited notable inter-RA differences.

Consistent with the results of many previous studies, vertical MSE advection and longwave radiative heating were found to be the largest sink and source of MJO MSE anomalies, respectively, although both terms exhibited marked inter-RA differences. The inter-RA spread in the contribution of wAdv to the maintenance of MSE anomaly was found to be mostly due to the differences in the magnitude anomalous vertical motion. The budget residual made significant contributions to the maintenance of MJO MSE anomalies, especially in the RAs where the net effect of vertical MSE advection and longwave radiative heating is large (MERRA2 and JRA-55), suggesting that the budget residual can be reduced by improving the two processes.

The analysis of the relationship between cloud-radiative feedback and CWV budget residual, originally performed by Yokoi (2015) with three RAs, was extended to the six RAs. We found a nearly linear relationship between them, confirming the results of Yokoi (2015). The cloud-radiation feedback parameter is also tightly correlated with vertical moisture advection. In MERRA-2 and JRA-55, cloud-radiation feedback was relatively weak and the CWV budget residual was positive. The opposite was the case in ERA-I. We also found a similar negative linear relationship between the convective adjustment time scale and CWV budget residual, and a significant positive correlation between the two parameters. 

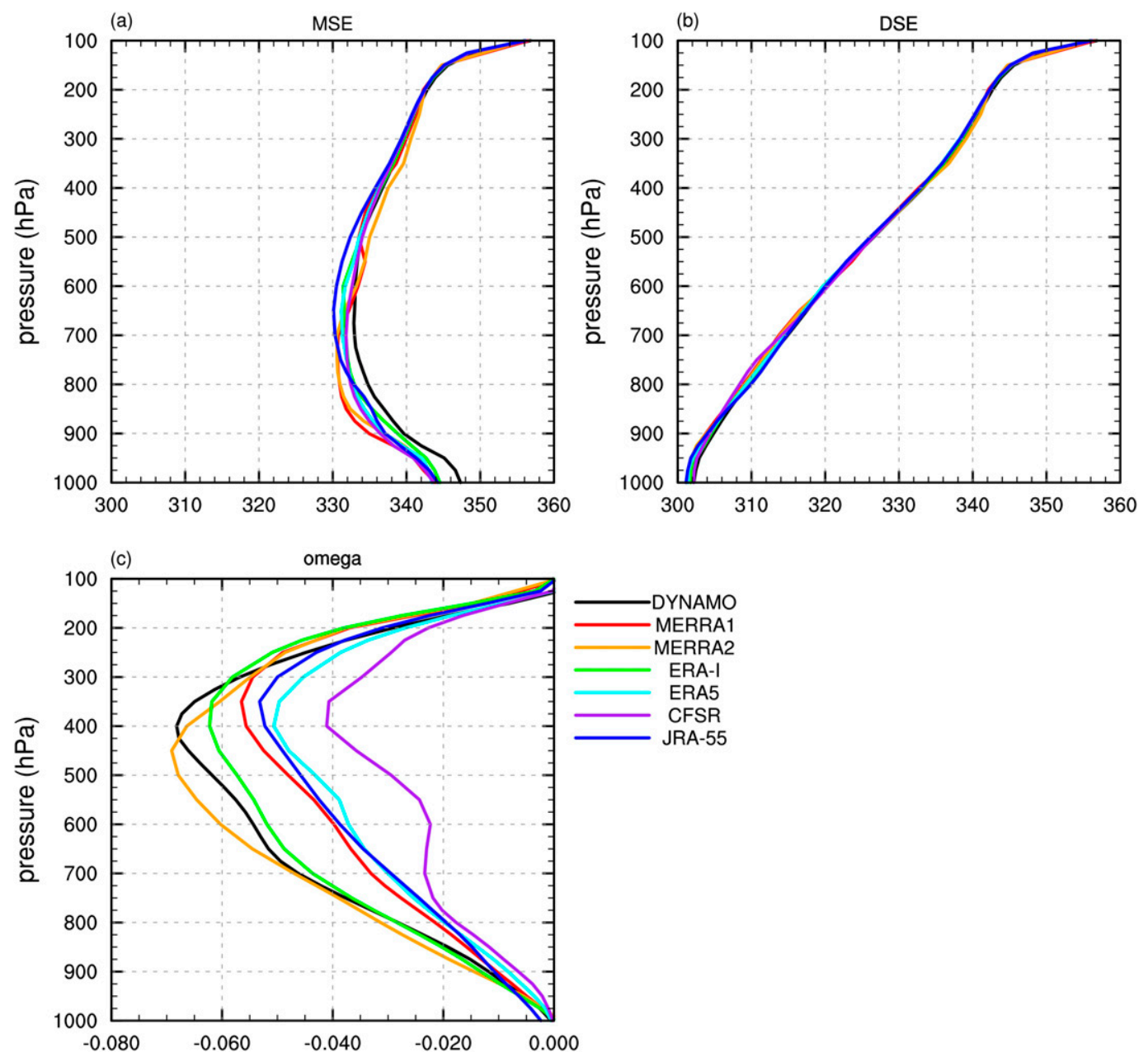

FIG. A1. Vertical profile of (a) MSE, (b) DSE, and (c) vertical motion during the DYNAMO period averaged over the NSA region.

Recent reanalysis intercomparison projects (e.g., Fujiwara et al. 2017; Schröder et al. 2019) have informed the users of the processes that are robust among different RAs and those that are represented differently between RAs. The knowledge about the uncertainty in RAs could prevent the users from drawing incorrect conclusions about the uncertain aspects in the RAs. Documenting the uncertain processes in RAs can also specify the area that needs attention in the future development of the RAs. In this study, we found the processes that are directly affected by the parameterization schemes of moist physics differ notably among the RAs and emphasized the vital role of moisture-cloud-radiation feedback on the maintenance of the MJO (e.g., Raymond 2001; Bony and Emanuel 2005; Kim et al. 2011, 2015; Yokoi 2015). More works need to be done to improve the representation of deep tropical convection and its interaction with humidity, cloud, and radiation in reanalysis products.

Acknowledgments. PR and HLR were both funded by the National Science Foundation (NSF) grant of China (Grant 41775066). DK was funded by the NOAA CVP program
(NA18OAR4310300), the DOE RGMA program (DESC0016223), the NASA MAP program (80NSSC17K0227), and the KMA R\&D program (KMI2018-03110). Work of the LLNL-affiliated author (MSA) was performed under the auspices of the U.S. Department of Energy by Lawrence Livermore National Laboratory under Contract DE-AC52-07NA27344 and their efforts were supported by the Regional and Global Climate Modeling Program of the United States Department of Energy's Office of Science. We thank Dr. Brandon Wolding and two anonymous reviewers for their constructive comments, which greatly helped improve an earlier version of the manuscript.

\section{APPENDIX}

\section{Testing the Constant NGMS Assumption Using DYNAMO Observations}

We compare the mean MSE, DSE, vertical velocity, and NGMS obtained from RAs to that from the DYNAMO field campaign data. We use the time averaged fields for the northern sounding array (NSA). The data were obtained from 
TABLE A1. Normalized gross moist stability during the dynamo period averaged around the NSA region.

\begin{tabular}{cccccccc}
\hline \hline & OBS & MERRA-1 & MERRA-2 & ERA-I & ERA5 & CFSR & JRA-55 \\
\hline$\tilde{M}$ & 0.21 & 0.34 & 0.30 & 0.27 & 0.29 & 0.30 & 0.31 \\
\hline
\end{tabular}

http://johnson.atmos.colostate.edu/dynamo/products/gridded/. The version that contains only observations (v3a) is used.

Figure A1 shows the vertical profiles of the mean MSE, DSE and vertical velocity from DYNAMO data and RAs. The mean MSE in RAs exhibit negative bias in the middle and lower troposphere. In addition, the level of the minimum MSE of MERRA2 is lower than those of other RAs, which affects the vertical gradient of MSE. In contrast, the mean DSE appears to be well constrained in RAs. Significant difference arises in the mean vertical velocity between RAs and they show a wide range of biases.

Table A1 shows the NGMS values over the NSA region in six RAs and DYNAMO observations. $\operatorname{NGMS}(\tilde{M})$ is obtained as follows:

$$
\tilde{M}=\omega \frac{\partial m}{\partial p} / \omega \frac{\partial s}{\partial p}
$$

where the meanings of the symbols follow that in the main text. While the six RAs show comparable values of $\tilde{M}(0.27-0.34)$, they are considerably higher than the observed value (0.21), suggesting that RAs have systematic bias of overestimating NGMS.

As in Yokoi (2015), Eq. (5) is used in this study under the assumption that there is no bias in NGMS. When the perfect NGMS assumption is relaxed, Eq. (5) takes the following form [Eq. (13) in Yokoi]:

$$
\frac{\hat{I}}{\hat{P}} \propto\left(\tilde{M}_{r}-1\right)\left(r-r_{r}\right)+\left(\tilde{M}-\tilde{M}_{r}\right)\left(1+r_{r}\right)
$$

where $\tilde{M}_{r}$ is NGMS in observations. The first and second terms on the RHS of Eq. (A2) are proportional to the bias in $r$ and in NGMS, respectively. Our calculation using the values in Table A1 shows that the first term on the RHS is more than 2 times larger than the second term, because inter-RA spread in NGMS is much smaller than that of $r$. Therefore, the difference among RAs in their vertical moisture advection is more strongly affected by the difference in $r$ than those in NGMS. It is worthwhile to note that the two quantities are not independent but negatively correlated (corr $=-0.43)$.

\section{REFERENCES}

Adames, Á. F., 2017: Precipitation budget of the Madden-Julian oscillation. J. Atmos. Sci., 74, 1799-1817, https://doi.org/ 10.1175/JAS-D-16-0242.1.

— , and J. M. Wallace, 2015: Three-dimensional structure and evolution of the moisture field in the MJO. J. Atmos. Sci., 72, 3733-3754, https://doi.org/10.1175/JAS-D-15-0003.1.

— , and D. Kim, 2016: The MJO as a dispersive, convectively coupled moisture wave: Theory and observations. J. Atmos. Sci., 73, 913-941, https://doi.org/10.1175/JAS-D-15-0170.1.

— J. M. Wallace, and J. M. Monteiro, 2016: Seasonality of the structure and propagation characteristics of the MJO. J. Atmos. Sci., 73, 3511-3526, https://doi.org/10.1175/JAS-D-15-0232.1.
—, D. Kim, A. H. Sobel, A. Del Genio, and J. Wu, 2017: Characterization of moist processes associated with changes in the propagation of the MJO with increasing CO2. J. $A d v$. Model. Earth Syst., 9, 2946-2967, https://doi.org/10.1002/ 2017MS001040.

$\longrightarrow,-$ E. D. Maloney, and A. H. Sobel, 2020: The moisture mode framework of the Madden-Julian Oscillation. The Multiscale Global Monsoon System, C. P. Chang et al., Eds., World Scientific Series on Asia-Pacific Weather and Climate, Vol. 11, World Scientific, 273-287, https://doi.org/10.1142/11723.

Ahmed, F., and C. Schumacher, 2018: Spectral signatures of moistureconvection feedbacks over the Indian Ocean. J. Atmos. Sci., 75, 1995-2015, https://doi.org/10.1175/JAS-D-17-0138.1.

Ahn, M., D. Kim, Y. Ham, and S. Park, 2020a: Role of Maritime Continent land convection on the mean state and MJO propagation. J. Climate, 33, 1659-1675, https://doi.org/10.1175/ JCLI-D-19-0342.1.

- , and Coauthors, 2020b: MJO propagation across the Maritime Continent: Are CMIP6 models better than CMIP5 models? Geophys. Res. Lett., 47, e2020GL087250, https://doi.org/10.1029/ 2020GL087250.

Andersen, J. A., and Z. Kuang, 2012: Moist static energy budget of MJO-like disturbances in the atmosphere of a zonally symmetric aquaplanet. J. Climate, 25, 2782-2804, https://doi.org/ 10.1175/JCLI-D-11-00168.1.

Arnold, N. P., and D. A. Randall, 2015: Global-scale convective aggregation: Implications for the Madden-Julian oscillation. J. Adv. Model. Earth Syst., 7, 1499-1518, https://doi.org/ 10.1002/2015MS000498.

_- Z. Kuang, and E. Tziperman, 2013: Enhanced MJO-like variability at high SST. J. Climate, 26, 988-1001, https:// doi.org/10.1175/JCLI-D-12-00272.1.

_- M. Branson, Z. Kuang, D. A. Randall, and E. Tziperman, 2015: MJO intensification with warming in the superparameterized CESM. J. Climate, 28, 2706-2724, https://doi.org/10.1175/ JCLI-D-14-00494.1.

Benedict, J. J., and D. A. Randall, 2007: Observed characteristics of the MJO relative to maximum rainfall. J. Atmos. Sci., 64, 2332-2354, https://doi.org/10.1175/JAS3968.1.

- M. S. Pritchard, and W. D. Collins, 2015: Sensitivity of MJO propagation to a robust positive Indian Ocean dipole event in the superparameterized CAM. J. Adv. Model. Earth Syst., 7, 1901-1917, https://doi.org/10.1002/2015MS000530.

Bladé, I., and D. L. Hartmann, 1993: Tropical intraseasonal oscillations in a simple nonlinear model. J. Atmos. Sci., 50, 2922-2939, https:// doi.org/10.1175/1520-0469(1993)050<2922:TIOIAS >2.0.CO;2.

Bony, S., and K. A. Emanuel, 2005: On the role of moist processes in tropical intraseasonal variability: Cloud-radiation and moisture-convection feedbacks. J. Atmos. Sci., 62, 2770-2789, https://doi.org/10.1175/JAS3506.1.

Bui, H. X., and E. D. Maloney, 2018: Changes in Madden-Julian oscillation precipitation and wind variance under global warming. Geophys. Res. Lett., 45, 7148-7155, https://doi.org/ 10.1029/2018GL078504.

Carlson, H., and R. Caballero, 2016: Enhanced MJO and transition to superrotation in warm climates. J. Adv. Model. Earth Syst., 8, 304-318, https://doi.org/10.1002/2015MS000615. 
Charney, J. G., 1963: A note on large-scale motions in the tropics. J. Atmos. Sci., 20, 607-609, https://doi.org/10.1175/15200469(1963)020<0607:ANOLSM > 2.0.CO;2.

Chen, G., and B. Wang, 2018: Effects of enhanced front Walker cell on the eastward propagation of the MJO. J. Climate, 31, 77197738, https://doi.org/10.1175/JCLI-D-17-0383.1.

—, T. Iwasaki, H. Qin, and W. Sha, 2014: Evaluation of the warm-season diurnal variability over East Asia in recent reanalyses JRA-55, ERA-Interim, NCEP CFSR, and NASA MERRA. J. Climate, 27, 5517-5537, https://doi.org/10.1175/ JCLI-D-14-00005.1.

Chen, X., J. Ling, and C. Li, 2016: Evolution of the Madden-Julian oscillation in two types of El Niño. J. Climate, 29, 1919-1934, https://doi.org/10.1175/JCLI-D-15-0486.1.

Chikira, M., 2014: Eastward-propagating intraseasonal oscillation represented by Chikira-Sugiyama cumulus parameterization. Part II: Understanding moisture variation under weak temperature gradient balance. J. Atmos. Sci., 71, 615-639, https:// doi.org/10.1175/JAS-D-13-038.1.

Das, S., D. Sengupta, and A. Chakraborty, 2019: The MaddenJulian oscillation in an aquaplanet-like general circulation model with and without continents. J. Adv. Model. Earth Syst., 11, 1459-1476, https://doi.org/10.1029/2018MS001455.

Dee, D. P., and Coauthors, 2011: The ERA-Interim reanalysis: Configuration and performance of the data assimilation system. Quart. J. Roy. Meteor. Soc., 137, 553-597, https://doi.org/ 10.1002/qj.828.

DeMott, C. A., J. J. Benedict, N. P. Klingaman, S. J. Woolnough, and D. A. Randall, 2016: Diagnosing ocean feedbacks to the MJO: SST-modulated surface fluxes and the moist static energy budget. J. Geophys. Res. Atmos., 121, 8350-8373, https:// doi.org/10.1002/2016JD025098.

—, N. P. Klingaman, W.-L. Tseng, M. A. Burt, Y. Gao, and D. A. Randall, 2019: The convection connection: How ocean feedbacks affect tropical mean moisture and MJO propagation. J. Geophys. Res. Atmos., 124, 11 910-11 931, https://doi.org/ 10.1029/2019JD031015.

Duchon, C. E., 1979: Lanczos filtering in one and two dimensions. J. Appl. Meteor., 18, 1016-1022, https://doi.org/10.1175/15200450(1979)018<1016:LFIOAT >2.0.CO;2.

Feng, J., T. Li, and W. Zhu, 2015: Propagating and nonpropagating MJO events over Maritime Continent. J. Climate, 28, 84308449, https://doi.org/10.1175/JCLI-D-15-0085.1.

Fuchs, Ž., and D. J. Raymond, 2017: A simple model of intraseasonal oscillations. J. Adv. Model. Earth Syst., 9, 1195-1211, https://doi.org/10.1002/2017MS000963.

Fujiwara, M., and Coauthors, 2017: Introduction to the SPARC Reanalysis Intercomparison Project (S-RIP) and overview of the reanalysis systems. Atmos. Chem. Phys., 17, 1417-1452, https://doi.org/10.5194/acp-17-1417-2017.

Gao, Y., P. C. Hsu, and H. H. Hsu, 2016: Assessments of surface latent heat flux associated with the Madden-Julian Oscillation in reanalyses. Climate Dyn., 47, 1755-1774, https://doi.org/ 10.1007/s00382-015-2931-4.

,-- , and T. Li, 2019: Effects of high-frequency activity on latent heat flux of MJO. Climate Dyn., 52, 1471-1485, https:// doi.org/10.1007/s00382-018-4208-1.

Gelaro, R., and Coauthors, 2017: The Modern-Era Retrospective Analysis for Research and Applications, version 2 (MERRA-2). J. Climate, 30, 5419-5454, https://doi.org/10.1175/JCLI-D16-0758.1.

Gonzalez, A. O., and X. Jiang, 2017: Winter mean lower tropospheric moisture over the Maritime Continent as a climate model diagnostic metric for the propagation of the MaddenJulian oscillation. Geophys. Res. Lett., 44, 2588-2596, https:// doi.org/10.1002/2016GL072430.

Hanf, F. S., H. Annamalai, A. Rinke, and K. Dethloff, 2017: South Asian summer monsoon breaks: Process-based diagnostics in HIRHAM5. J. Geophys. Res. Atmos., 122, 4880-4902, https:// doi.org/10.1002/2016JD025967.

Hannah, W. M., and E. D. Maloney, 2014: The moist static energy budget in NCAR CAM5 hindcasts during DYNAMO. J. Adv. Model. Earth Syst., 6, 420-440, https://doi.org/10.1002/ 2013MS000272.

,-- , and M. S. Pritchard, 2015: Consequences of systematic model drift in DYNAMO MJO hindcasts with SP-CAM and CAM5. J. Adv. Model. Earth Syst., 7, 1051-1074, https:// doi.org/10.1002/2014MS000423.

Hersbach, H., and Coauthors, 2019: Global reanalysis: Goodbye ERA-Interim, hello ERA5. ECMWF Newsletter, No. 159, ECMWF, Reading, United Kingdom, 17-24, https://www. ecmwf.int/sites/default/files/elibrary/2019/19027-global-reanalysisgoodbye-era-interim-hello-era5.pdf.

Hill, S. A., Y. Ming, and I. M. Held, 2017: Mechanisms of forced tropical meridional energy flux change. J. Climate, 28, 17251742, https://doi.org/10.1175/JCLI-D-14-00165.1.

Hsu, P., and T. Xiao, 2017: Differences in the initiation and development of the Madden-Julian oscillation over the Indian Ocean associated with two types of El Niño. J. Climate, 30, 1397-1415, https://doi.org/10.1175/JCLI-D-16-0336.1.

—, T. Li, and H. Murakami, 2014: Moisture asymmetry and MJO eastward propagation in an aquaplanet general circulation model. J. Climate, 27, 8747-8760, https://doi.org/10.1175/JCLID-14-00148.1.

Huang, Y., Y. Wang, and X. Cui, 2019: Differences between convective and stratiform precipitation budgets in a torrential rainfall event. Adv. Atmos. Sci., 36, 495-509, https://doi.org/ 10.1007/s00376-019-8159-1.

Hung, C., and C. Sui, 2018: A diagnostic study of the evolution of the MJO from Indian Ocean to Maritime Continent: Wave dynamics versus advective moistening processes. J. Climate, 31, 4095-4115, https://doi.org/10.1175/JCLI-D-17-0139.1.

Inness, P. M., J. M. Slingo, S. J. Woolnough, R. B. Neale, and V. D. Pope, 2001: Organization of tropical convection in a GCM with varying vertical resolution; implications for the simulation of the Madden-Julian oscillation. Climate Dyn., 17, 777793, https://doi.org/10.1007/s003820000148.

Inoue, K., and L. E. Back, 2015: Gross moist stability assessment during TOGA COARE: Various interpretations of gross moist stability. J. Atmos. Sci., 72, 4148-4166, https://doi.org/ 10.1175/JAS-D-15-0092.1.

Jiang, X. A., 2017: Key processes for the eastward propagation of the Madden-Julian oscillation based on multimodel simulations. J. Geophys. Res. Atmos., 122, 755-770, https://doi.org/ 10.1002/2016JD025955.

—, M. Zhao, E. D. Maloney, and D. E. Waliser, 2016: Convective moisture adjustment time scale as a key factor in regulating model amplitude of the Madden-Julian oscillation. Geophys. Res. Lett., 43, $10412-10419$, https://doi.org/ 10.1002/2016GL070898.

—, Á. F. Adames, M. Zhao, D. Waliser, and E. Maloney, 2018: A Unified moisture mode framework for seasonality of the Madden-Julian oscillation. J. Climate, 31, 4215-4224, https:// doi.org/10.1175/JCLI-D-17-0671.1.

_ , and Coauthors, 2020: Fifty years of research on the MaddenJulian oscillation: Recent progress, challenges, and perspectives. 
J. Geophys. Res. Atmos., 125, e2019JD030911, https://doi.org/ 10.1029/2019JD030911.

Johnson, R. H., T. M. Rickenbach, S. A. Rutledge, P. E. Ciesielski, and W. H. Schubert, 1999: Trimodal characteristics of tropical convection. J. Climate, 12, 2397-2418, https://doi.org/10.1175/ 1520-0442(1999)012<2397:TCOTC $>2.0$. CO;2.

Kalnay, E. M., and Coauthors, 1996: The NCEP/NCAR 40-Year Reanalysis Project. Bull. Amer. Meteor. Soc., 77, 437-471, https:// doi.org/10.1175/1520-0477(1996)077<0437:TNYRP>2.0.CO;2.

Kanamitsu, M., W. Ebisuzaki, J. Woollen, S. Yang, J. J. Hnilo, M. Fiorino, and G. L. Potter, 2002: NCEP-DOE AMIP-II Reanalysis (R-2). Bull. Amer. Meteor. Soc., 83, 1631-1644, https://doi.org/10.1175/BAMS-83-11-1631.

Kang, D., D. Kim, M. S. Ahn, R. Neale, J. Lee, and P. J. Gleckler, 2020: The role of the mean state on MJO simulation in CESM 2 ensemble simulation. Geophys. Res. Lett., 47, e2020GL089824, https://doi.org/10.1029/2020GL089824.

Kemball-Cook, S. R., and B. C. Weare, 2001: The onset of convection in the Madden-Julian oscillation. J. Climate, 14, 780-793, https://doi.org/10.1175/1520-0442(2001)014<0780: TOOCIT $>2.0 . \mathrm{CO} ; 2$.

Khairoutdinov, M. F., and K. Emanuel, 2018: Intraseasonal variability in a cloud-permitting near-global equatorial aquaplanet model. J. Atmos. Sci., 75, 4337-4355, https://doi.org/ 10.1175/JAS-D-18-0152.1.

Kiladis, G. N. J., K. H. Dias, M. C. Straub, S. N. Wheeler, K. Tulich, K. M. Kikuchi, and M. J. Weickmann, 2014: A comparison of OLR and circulation-based indices for tracking the MJO. Mon. Wea. Rev., 142, 1697-1715, https://doi.org/10.1175/MWR-D-1300301.1 .

Kim, D., and Coauthors, 2009: Application of MJO simulation diagnostics to climate models. J. Climate, 22, 6413-6436, https://doi.org/10.1175/2009JCLI3063.1.

, A. H. Sobel, E. D. Maloney, D. M. W. Frierson, and I. Kang, 2011: A systematic relationship between intraseasonal variability and mean state bias in AGCM simulations. J. Climate, 24, 5506-5520, https://doi.org/10.1175/2011JCLI4177.1.

— J. Kug, and A. H. Sobel, 2014a: Propagating versus nonpropagating Madden-Julian oscillation events. J. Climate, 27, 111-125, https://doi.org/10.1175/JCLI-D-13-00084.1.

— M. Lee, D. Kim, S. Schubert, D. Waliser, and B. Tian, 2014b: Representation of tropical subseasonal variability of precipitation in global reanalyses. Climate Dyn., 43, 517-534, https:// doi.org/10.1007/s00382-013-1890-x.

_ M. Ahn, I. Kang, and A. D. Del Genio, 2015: Role of longwave cloud-radiation feedback in the simulation of the Madden-Julian oscillation. J. Climate, 28, 6979-6994, https:// doi.org/10.1175/JCLI-D-14-00767.1.

- H. Kim, and M.-I. Lee, 2017: Why does the MJO detour the Maritime Continent during austral summer? Geophys. Res. Lett., 44, 2579-2587, https://doi.org/10.1002/2017GL072643.

Kim, H.-M., 2017: The impact of the mean moisture bias on the key physics of MJO propagation in the ECMWF reforecast. J. Geophys. Res. Atmos., 122, 7772-7784, https://doi.org/10.1002/ 2017JD027005.

Kiranmayi, L., and E. D. Maloney, 2011: Intraseasonal moist static energy budget in reanalysis data. J. Geophys. Res., 116, D21117, https://doi.org/10.1029/2011JD016031.

Kobayashi, S., and Coauthors, 2015: The JRA-55 reanalysis: General specifications and basic characteristics. J. Meteor. Soc. Japan, 93, 5-48, https://doi.org/10.2151/jmsj.2015-001.

Kummerow, C., and Coauthors, 2000: The status of the Tropical Rainfall Measuring Mission (TRMM) after two years in orbit.
J. Appl. Meteor., 39, 1965-1982, https://doi.org/10.1175/15200450(2001)040<1965:TSOTTR > 2.0.CO;2.

Lau, K.-M., and P. H. Chan, 1986: Aspects of the 40-50 day oscillation during the northern summer as inferred from outgoing longwave radiation. Mon. Wea. Rev., 114, 1354-1367, https://doi.org/ 10.1175/1520-0493(1986)114<1354:AOTDOD>2.0.CO;2.

Lau, W. K. M., and D. E. Waliser, Eds., 2012: Intraseasonal Variability in the Atmosphere-Ocean Climate System. 2nd ed. Springer, $614 \mathrm{pp}$.

Liebmann, B., and C. Smith, 1996: Description of a complete (interpolated) outgoing longwave radiation dataset. Bull. Amer. Meteor. Soc., 77, 1275-1277, https://doi.org/10.1175/15200477-77.6.1274.

Lindsay, R., M. Wensnahan, A. Schweiger, and J. Zhang, 2014: Evaluation of seven different atmospheric reanalysis products in the Arctic. J. Climate, 27, 2588-2606, https://doi.org/10.1175/ JCLI-D-13-00014.1.

Ling, J., Y. Zhao, and G. Chen, 2019: Barrier effect on MJO propagation by the Maritime Continent in the MJO Task Force/GEWEX Atmospheric System Study models. J. Climate, 32, 5529-5547, https://doi.org/10.1175/JCLI-D-18-0870.1.

Madden, R. A., and P. R. Julian, 1971: Detection of a 40-50 day oscillation in the zonal wind in the tropical Pacific. J. Atmos. Sci., 28, 702-708, https://doi.org/10.1175/1520-0469(1971) $028<0702$ :DOADOI $>2.0$. CO 2 .

$\longrightarrow$, and - 1972: Description of global-scale circulation cells in the tropics with a 40-50 day period. J. Atmos. Sci., 29, 11091123, https://doi.org/10.1175/1520-0469(1972)029<1109: DOGSCC $>2.0 . \mathrm{CO} ; 2$.

Maloney, E. D., 2009: The moist static energy budget of a composite tropical intraseasonal oscillation in a climate model. J. Climate, 22, 711-729, https://doi.org/10.1175/2008JCLI2542.1.

— cillation in an aquaplanet general circulation model. $J$. $A d v$. Model. Earth Syst., 7, 1956-1976, https://doi.org/10.1002/ 2015MS000495.

_ A. H. Sobel, and W. M. Hannah, 2010: Intraseasonal variability in an aquaplanet general circulation model. J. Adv. Model. Earth Syst., 2, 5, https://doi.org/10.3894/JAMES.2010.2.5.

Mapes, B. E., and J. T. Bacmeister, 2012: Diagnosis of tropical biases and the MJO from patterns in the MERRA analysis tendency fields. J. Climate, 25, 6202-6214, https://doi.org/ 10.1175/JCLI-D-11-00424.1.

Murakami, T., T. Nakazawa, and J. He, 1984: On the 40-50 day oscillations during the 1979 Northern Hemisphere summer. Part I: Phase propagation. J. Meteor. Soc. Japan, 62, 440-468, https://doi.org/10.2151/jmsj1965.62.3_440.

Pillai, P. A., and A. K. Sahai, 2016: Moisture dynamics of the northward and eastward propagating boreal summer intraseasonal oscillations: Possible role of tropical Indo-west Pacific SST and circulation. Climate Dyn., 47, 1335-1350, https://doi.org/10.1007/s00382-015-2904-7.

Pritchard, M. S., and D. Yang, 2016: Response of the superparameterized Madden-Julian oscillation to extreme climate and basic-state variation challenges a moisture mode view. J. Climate, 29, 4995-5008, https://doi.org/10.1175/JCLI-D-150790.1.

Raymond, D. J., 2001: A new model of the Madden-Julian oscillation. J. Atmos. Sci., 58, 2807-2819, https://doi.org/10.1175/ 1520-0469(2001)058<2807:ANMOTM>2.0.CO;2.

— , S. L. Sessions, A. H. Sobel, and Ž. Fuchs, 2009: The mechanics of gross moist stability. J. Adv. Model. Earth Syst., 1, 9 , https://doi.org/10.3894/JAMES.2009.1.9. 
Ren, H.-L., and P. Ren, 2017: Impact of Madden-Julian oscillation upon winter extreme rainfall in southern China: Observations and predictability in CFSv2. Atmosphere, 8, 192, https:// doi.org/10.3390/atmos8100192.

Ren, P., H.-L. Ren, J.-X. Fu, J. Wu, and L. Du, 2018: Impact of boreal summer intraseasonal oscillation on rainfall extremes in southeastern China and its predictability in CFSv2. J. Geophys. Res. Atmos., 123, 4423-4442, https://doi.org/ 10.1029/2017JD028043.

Rienecker, M. M., and Coauthors, 2011: MERRA: NASA's Modern-Era Retrospective Analysis for Research and Applications. J. Climate, 24, 3624-3648, https://doi.org/ 10.1175/JCLI-D-11-00015.1.

Saha, S., and Coauthors, 2010: The NCEP Climate Forecast System Reanalysis. Bull. Amer. Meteor. Soc., 91, 1015-1058, https:// doi.org/10.1175/2010BAMS3001.1.

— version 2. J. Climate, 27, 2185-2208, https://doi.org/10.1175/ JCLI-D-12-00823.1.

Sakaeda, N., and P. E. Roundy, 2016: Gross moist stability and the Madden-Julian oscillation in reanalysis data. Quart. J. Roy. Meteor. Soc., 142, 2740-2757, https://doi.org/10.1002/ qj.2865.

Schröder, M., and Coauthors, 2019: The GEWEX water vapor assessment: Overview and introduction to results and recommendations. Remote Sens., 11, 251, https://doi.org/10.3390/ rs11030251.

Seo, H., A. C. Subramanian, A. J. Miller, and N. R. Cavanaugh, 2014: Coupled impacts of the diurnal cycle of sea surface temperature on the Madden-Julian oscillation. J. Climate, 27, 8422-8443, https://doi.org/10.1175/JCLI-D-14-00141.1.

Shi, X., D. Kim, Á. F. Adames, and J. Sukhatme, 2018: WISHE-moisture mode in an aquaplanet simulation. J. Adv. Model. Earth Syst., 10, 2393-2407, https://doi.org/ 10.1029/2018MS001441.

Sobel, A. H., and E. D. Maloney, 2012: An idealized semi-empirical framework for modeling the Madden-Julian oscillation. J. Atmos. Sci., 69, 1691-1705, https://doi.org/10.1175/JAS-D11-0118.1.

— tion of the MJO. J. Atmos. Sci., 70, 187-192, https://doi.org/ 10.1175/JAS-D-12-0189.1.

__ J. Nilsson, and L. M. Polvani, 2001: The weak temperature gradient approximation and balanced tropical moisture waves. J. Atmos. Sci., 58, 3650-3665, https://doi.org/10.1175/15200469(2001)058<3650:TWTGAA > 2.0.CO;2.

_ - S. Wang, and D. Kim, 2014: Moist static energy budget of the MJO during DYNAMO. J. Atmos. Sci., 71, 4276-4291, https:// doi.org/10.1175/JAS-D-14-0052.1.

Sooraj, K. P., and K. Seo, 2013: Boreal summer intraseasonal variability simulated in the NCEP Climate Forecast System: Insights from moist static energy budget and sensitivity to convective moistening. Climate Dyn., 41, 1569-1594, https:// doi.org/10.1007/s00382-012-1631-6.

Stan, C., 2018: The role of SST variability in the simulation of the MJO. Climate Dyn., 51, 2943-2964, https://doi.org/10.1007/ s00382-017-4058-2.

Subramanian, A. C., and G. J. Zhang, 2014: Diagnosing MJO hindcast biases in NCAR CAM3 using nudging during the DYNAMO field campaign. J. Geophys. Res. Atmos., 119, 7231-7253, https://doi.org/10.1002/2013JD021370.

Takasuka, D., M. Satoh, T. Miyakawa, and H. Miura, 2018: Initiation processes of the tropical intraseasonal variability simulated in an aqua-planet experiment: What is the intrinsic mechanism for MJO onset? J. Adv. Model. Earth Syst., 10, 1047-1073, https://doi.org/10.1002/2017MS001243.

Thayer-Calder, K., and D. A. Randall, 2009: The role of convective moistening in the Madden-Julian oscillation. J. Atmos. Sci., 66, 3297-3312, https://doi.org/10.1175/2009JAS3081.1.

Tseng, K., C. Sui, and T. Li, 2015: Moistening processes for MaddenJulian oscillations during DYNAMO/CINDY. J. Climate, 28, 3041-3057, https://doi.org/10.1175/JCLI-D-14-00416.1.

Wang, B., 2012: Theory. Intraseasonal Variability in the AtmosphereOcean Climate System, 2nd ed. W. K. M. Lau and D. E. Waliser, Eds., Springer, 335-398.

— system. Part I: The role of air-sea interaction in maintaining Madden-Julian oscillation. J. Climate, 11, 2116-2135, https:// doi.org/10.1175/1520-0442-11.8.2116.

Wang, L., T. Li, E. Maloney, and B. Wang, 2017: Fundamental causes of propagating and nonpropagating MJOs in MJOTF/ GASS models. J. Climate, 30, 3743-3769, https://doi.org/ 10.1175/JCLI-D-16-0765.1.

Wang, S., A. H. Sobel, F. Zhang, Y. Q. Sun, Y. Yue, and L. Zhou, 2015: Regional simulation of the October and November MJO events observed during the CINDY/DYNAMO field campaign at gray zone resolution. J. Climate, 28, 2097-2119, https://doi.org/10.1175/JCLI-D-14-00294.1.

Wang, T., and T. Li, 2020: Effect of vertical moist static energy advection on MJO eastward propagation: Sensitivity to analysis domain. Climate Dyn., 54, 2029-2039, https://doi.org/ 10.1007/s00382-019-05101-8.

Wei, Y., and H. Ren, 2019: Modulation of ENSO on fast and slow MJO modes during boreal winter. J. Climate, 32, 7483-7506, https://doi.org/10.1175/JCLI-D-19-0013.1.

Wheeler, M. C., and H. H. Hendon, 2004: An all-season realtime multivariate MJO index: Development of an index for monitoring and prediction. Mon. Wea. Rev., 132, 19171932, https://doi.org/10.1175/1520-0493(2004)132<1917: AARMMI $>2.0 . \mathrm{CO} ; 2$.

Wolding, B. O., and E. D. Maloney, 2015: Objective diagnostics and the Madden-Julian oscillation. Part II: Application to moist static energy and moisture budgets. J. Climate, 28, 77867808, https://doi.org/10.1175/JCLI-D-14-00689.1.

,-- , and M. Branson, 2016: Vertically resolved weak temperature gradient analysis of the Madden-Julian oscillation in SP-CESM. J. Adv. Model. Earth Syst., 8, 1586-1619, https:// doi.org/10.1002/2016MS000724.

,,-- S. Henderson, and M. Branson, 2017: Climate change and the Madden-Julian oscillation: A vertically resolved weak temperature gradient analysis. J. Adv. Model. Earth Syst., 9, 307-331, https://doi.org/10.1002/2016MS000843.

Wu, X., and L. Deng, 2013: Comparison of moist static energy and budget between the GCM-simulated Madden-Julian oscillation and observations over the Indian Ocean and western Pacific. J. Climate, 26, 4981-4993, https://doi.org/10.1175/ JCLI-D-12-00607.1.

Yasunaga, K., S. Yokoi, K. Inoue, and B. E. Mapes, 2019: Spacetime spectral analysis of the moist static energy budget equation. J. Climate, 32, 501-529, https://doi.org/10.1175/ JCLI-D-18-0334.1.

Yasunari, T., 1979: Cloudiness fluctuations associated with the Northern Hemisphere summer monsoon. J. Meteor. Soc. Japan, 57, 227-242, https://doi.org/10.2151/jmsj1965.57.3_227.

_ 1980: A quasi-stationary appearance of 30-40 day period in the cloudiness fluctuations during the summer monsoon over 
India. J. Meteor. Soc. Japan, 58, 225-229, https://doi.org/ 10.2151/jmsj1965.58.3_225.

Yokoi, S., 2015: Multireanalysis comparison of variability in column water vapor and its analysis increment associated with the Madden-Julian oscillation. J. Climate, 28, 793-808, https:// doi.org/10.1175/JCLI-D-14-00465.1.

— , and A. Sobel, 2015: Intraseasonal variability and seasonal march of the moist static energy budget over the eastern Maritime Continent during CINDY2011/DYNAMO. J. Meteor. Soc. Japan, 93A, 81-100, https://doi.org/10.2151/jmsj.2015-041.

Zhang, C., 2005: Madden-Julian oscillation. Rev. Geophys., 43, RG2003, https://doi.org/10.1029/2004RG000158.
- 2013: Madden-Julian oscillation: Bridging weather and climate. Bull. Amer. Meteor. Soc., 94, 1849-1870, https://doi.org/ 10.1175/BAMS-D-12-00026.1.

, M. Dong, S. Gualdi, H. Hendon, E. Maloney, A. Marshall, K. Sperber, and W. Wang, 2006: Simulations of the MaddenJulian oscillation in four pairs of coupled and uncoupled global models. Climate Dyn., 27, 573-592, https://doi.org/ 10.1007/s00382-006-0148-2.

Á. F. Adames, B. Khouider, B. Wang, and D. Yang, 2020: Four theories of the Madden-Julian Oscillation. Rev. Geophys., 58, e2019RG000685, https://doi.org/10.1029/ 2019RG000685. 